Check for updates

Cite this: Sustainable Energy Fuels, 2018, 2, 2583

Received 15th June 2018

Accepted 15th October 2018

DOI: $10.1039 / \mathrm{c} 8 \mathrm{se} 00281 \mathrm{a}$

rsc.li/sustainable-energy

\section{Engineering photoautotrophic carbon fixation for enhanced growth and productivity}

\begin{abstract}
Feiyan Liang, Pia Lindberg and Peter Lindblad (D)*
Oxygenic photosynthesis is the origin of most organic carbon compounds on Earth and an essential part of the natural carbon cycle. Cyanobacteria, the only oxygenic photoautotrophic prokaryotes, are important in several natural processes: as primary sustainable producers, in providing oxygen to the atmosphere, and in nitrogen fixation. From a biotechnological perspective, cyanobacteria are ideal cell factories since (i) the required energy and carbon source, sunlight and $\mathrm{CO}_{2}$, are abundant and freely available, (ii) cyanobacteria are capable of producing a variety of natural products, which can be used as fuels, medicines, cosmetics etc., and (iii) metabolic engineering and synthetic biology tools of cyanobacteria are being developed rapidly, making them feasible as host organisms for heterologous production of interesting compounds. However, compared to commercially employed heterotrophic microorganisms, the growth and productivity of cyanobacteria are currently not competitive. Therefore, improving cyanobacterial growth and productivity is an important task to enable commercialization of cyanobacterial bioproducts. Such studies also offer important clues for increasing the photosynthesis and yield of crop plants, which is important in view of providing food for a rapidly increasing world population. There are many strategies targeting this task, such as optimizing cultivation conditions, engineering native pathways, and introducing synthetic pathways based on an understanding of overall metabolic networks. One major limitation of cyanobacterial productivity, however, is the low efficiency of carbon fixation through the Calvin-Benson-Bassham (CBB) cycle. In this review, we introduce and discuss the possibilities to enhance growth and productivity by engineering the CBB cycle. We also give a brief discussion of options to further extend the capabilities of cells to fix inorganic carbon by the introduction of other native and artificial carbon fixation cycles.
\end{abstract}

\section{Introduction}

It is predicted that by 2050 , the world population will increase by at least $30 \%$ compared to 2015 . Together with increased daily food consumption per individual, a $50 \%$ increase in food production will be required. It is impossible to meet this demand only by expanding the arable lands. Therefore, high yield crops and/or non-crop food will be needed. Similar to the situation with food, a much larger energy supply will also be required in the future. The energy used today is mainly fossil fuels, usage of which must be diminished due to air pollution and global warming. Therefore, increasing the crop yield and finding alternatives to fossil fuels are two of the major tasks that modern society is facing.

Food and fossil fuels both originate from oxygenic photosynthesis, which consists of a photochemical phase and a second biosynthetic phase. In the photochemical phase, solar energy is absorbed and converted into chemical energy. During this process, water is split, releasing oxygen and protons into

Microbial Chemistry, Department of Chemistry-Ångström, Uppsala, Sweden. E-mail: peter.lindblad@kemi.uu.se the thylakoid lumen. At the same time, the released electrons enter the photosynthetic electron transfer chain. In the electron transfer chain, plastoquinone is reduced to plastoquinol, transferring electrons to the cytochrome $b_{6} f$ complex. When plastoquinol is oxidized back to plastoquinone, protons are transferred from the cytoplasm to the thylakoid lumen., ${ }^{1,2}$ Finally, the electrons are used to reduce $\mathrm{NADP}^{+}$into NADPH, and the generated proton gradient between the thylakoid lumen and cytoplasm drives ATP synthesis with an ATP synthase. $\mathrm{NADPH}$ is subsequently used in the so-called biosynthetic phase, where $\mathrm{CO}_{2}$ is assimilated to generate the building blocks of amino acids and other carbon-containing molecules, at the same time consuming ATP and NADPH.

One method to obtain food and renewable fuels from the oxygenic photosynthetic process is to supply plant biomass to Escherichia coli (E. coli), yeasts or other well understood microorganisms for fermentation to get the desired compound(s). However, due to the multiple steps in this process, from energy absorption by plants to fermentation by heterotrophic organisms, the solar energy-to-product efficiency is very low, for example $0.2 \%$ in ethanol production from sugarcane fermentation. ${ }^{3}$ In addition, E. coli and yeasts are not able to ferment all 
types of plant biomass components. For example, the most abundant carbohydrate, lignocellulose from plant materials, needs to be broken down into smaller molecules before it can be used. This breaking down process requires enzymes, high temperature, or/and high pressure. ${ }^{4}$ Besides, using crop plants as the source of sugar for fermentation is not a viable alternative on a large scale, as it would lead to less arable land available for food production.

Another method to generate renewable fuels would be to directly obtain them from autotrophic microorganisms like cyanobacteria or microalgae. Using such organisms as green cell factories or cell catalysts has many advantages over traditional fermentation technologies. Cyanobacteria and microalgae use cheap and abundant energy (sunlight) and carbon $\left(\mathrm{CO}_{2}\right)$ sources, and also show a higher energy conversion efficiency compared to land plants (e.g. 1.5\% in oil production from microalgae). ${ }^{5}$ Cyanobacteria, being prokaryotes, are relatively easy to engineer compared to eukaryotic organisms. Ideal cyanobacterial cell factories are those that can maintain the cell population, distribute the remaining energy and carbon to the designed product(s), and possess the capability to excrete the product(s) out of the cells. Excreting products will minimize any potential toxicities or other negative effects on the cell metabolism, simplify recovery, and may also increase the yield..$^{6,7}$

While the main advantage of cyanobacteria as cell factories compared to heterotrophic microorganisms is their capability for oxygenic photosynthesis, the main drawback is the relatively low yields achieved per volume and time in bioreactors, requiring large scale facilities and a large surface area. ${ }^{\mathbf{8 - 1 0}}$ The main reason for this is the limitations inherent to photosynthesis, and thus, increasing the photosynthetic efficiency is necessary to enhance the yield and to realize commercialization of cyanobacterial products. The photosynthetic efficiency is determined as the sum efficiency of the photochemical and biosynthetic phases. In this review, we will focus on the biosynthetic phase, discussing the control enzymes of the Calvin-Benson-Bassham (CBB) carbon fixation cycle and other natural and artificial carbon fixation cycles. Some other possible strategies to enhance growth and productivity will also be briefly discussed.

\section{The Calvin-Benson-Bassham (CBB) cycle}

The CBB cycle, employing one of the most abundant but also one of the least efficient enzymes in nature, ribulose-1,5bisphosphate carboxylase (RuBisCO), to fix $\mathrm{CO}_{2}$, is the major carbon fixation cycle in nature. It consists of 13 reactions catalysed by 11 enzymes (Fig. 1). The entire cycle is divided into 3 stages: (i) ribulose-1,5-bisphosphate (RuBP) carboxylation, (ii) 3phosphoglycerate (PGA) reduction, and (iii) RuBP regeneration. In the carboxylation stage, RuBisCO catalyses one molecule of $\mathrm{CO}_{2}$ and one molecule of RuBP to form two molecules of PGA. The PGA is converted into glyceraldehyde-3-phosphate (GAP), consuming ATP and NADPH generated in the photochemical phase in the reduction stage. Finally, RuBP is regenerated from
GAP through several steps, also consuming ATP in the RuBP regeneration stage. Without considering the side reaction of RuBisCO where the substrate is oxygen (photorespiration), nine molecules of ATP and six molecules of NADPH are required to assimilate three molecules of $\mathrm{CO}_{2}$ and to generate one molecule of GAP in the CBB cycle.

The cyanobacterial CBB cycle partially overlaps the oxidative pentose phosphate (OPP) pathway, the main NADPH supplier, under heterotrophic growth conditions. However, three steps are specific in the CBB cycle (Fig. 1). They are (i) fixing $\mathrm{CO}_{2}$ into PGA by RuBisCO (consumption of RuBP), (ii) phosphorylating ribulose-5-phosphate (Ru5P) to RuBP by phosphoribulokinase (PRK, regeneration of $\mathrm{RuBP}$ ), and (iii) dephosphorylating sedoheptulose-1,7-bisphosphate (SBP) into sedoheptulose-7phosphate (S7P) by the bi-functional enzyme FBP/SBPase, a step in which photoautotrophic eukaryotes are catalysed by SBPase. Generally, chloroplast FBPase in plants is able to catalyse conversions between SBP and S7P; however, the catalytic rate is too low to support a normal autotrophic growth. ${ }^{\mathbf{1 1}}$ Introducing RuBisCO and PRK into a heterotrophic microorganism would theoretically complete the CBB cycle. Together with an appropriate energy supply, introducing RuBisCO and PRK would allow heterotrophic microorganisms to fix $\mathrm{CO}_{2}$ into carbohydrates. ${ }^{12}$ Re-fixing the $\mathrm{CO}_{2}$ released during the carbon metabolism is a promising strategy to increase the carbon usage efficiency in heterotrophic microorganisms. Therefore, studying the CBB cycle and increasing its efficiency will potentially have beneficial effects on the efficiencies of both autotrophic and heterotrophic cell factories.

The CBB cycle is one of the limitations to higher yield and some of its enzymes are more critical than others for the overall efficiency. Therefore, identifying these steps and the corresponding enzymes is the first step towards enhancing the CBB cycle efficiency and subsequently productivity, and technologies to achieve this have been developed. Generally, increasing or decreasing the catalytic efficiency of enzyme(s) will accordingly increase or decrease the flux through the pathway. Analysis of the metabolism following enzyme engineering is one of the methods to determine the critical step(s). In this method, the term "flux control co-efficient" is used, which is determined by calculating the ratio between the change of flux and the change of specific enzyme activity under certain growth conditions. ${ }^{\mathbf{1 3}}$ The value varies between 0 (no control) and 1 (full control). In many cases, the full control comes from several enzymes, of which one of them is critical. Two things should be kept in mind: (i) specific growth conditions may be required for an enzyme to show control on the flux through the pathway, and the flux control co-efficient varies under different cultivation conditions; (ii) significant changes of the enzyme are required to detect the flux change when the capacity of the enzyme is much higher than the natural capacity of the pathway. In this case, a small flux control coefficient is expected; in other words, the enzyme is not a flux-controlling enzyme under many cultivation conditions. In the early 1990s, numerous studies on antisense plants with deduced CBB cycle enzymes explored the flux control coefficient and physiological features under different growth conditions. Table 1 summarises these studies. 


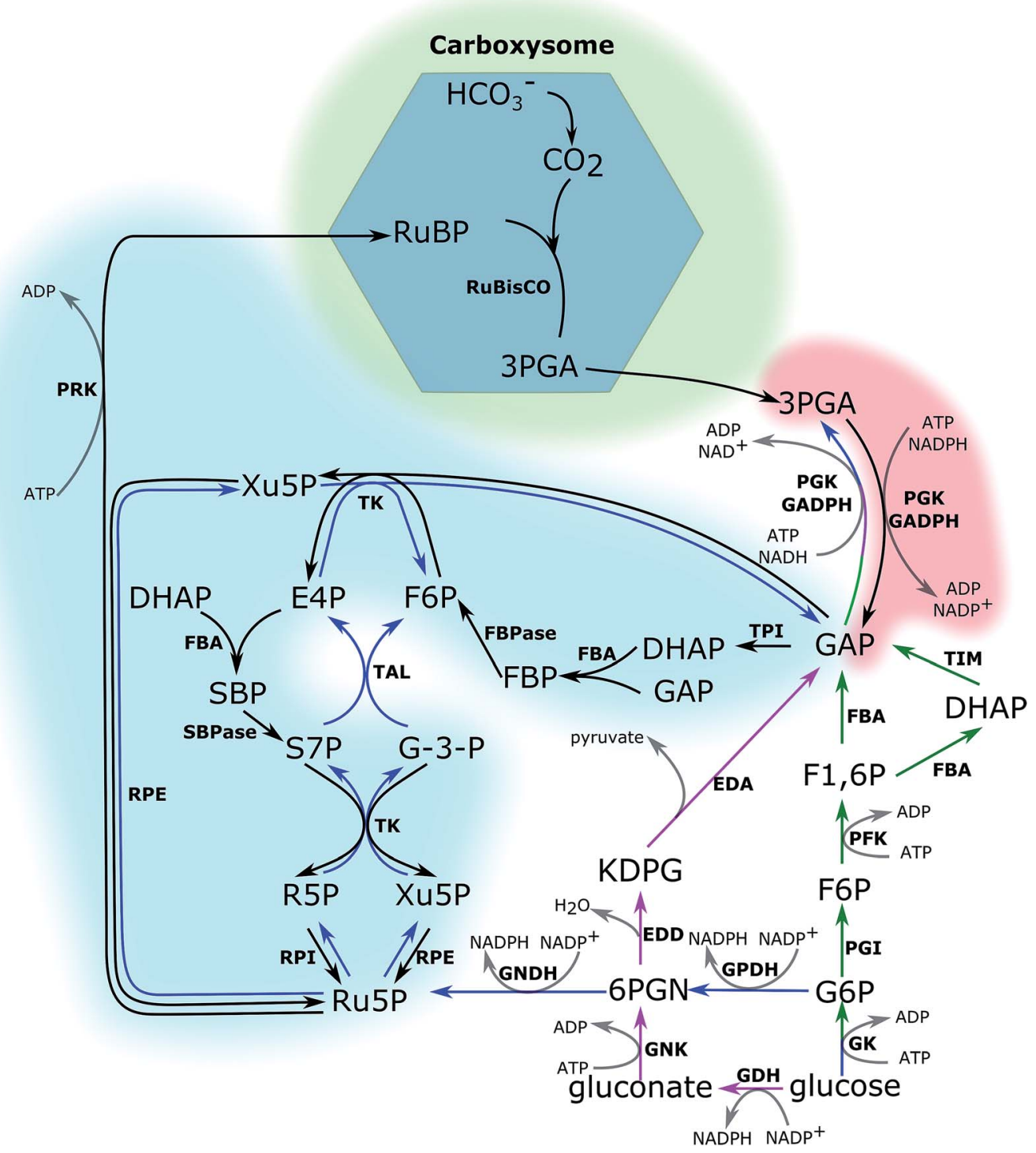

Fig. 1 Central carbon metabolic pathways in cyanobacteria. The Calvin-Benson-Bassham (CBB) cycle (black), Oxidative Pentose Phosphate (OPP) pathway (blue), glycolysis pathway (green), and Entner-Doudoroff (ED) pathway (purple). Green, red and blue shadows indicate carboxylation, PGA reduction and RuBP regeneration stages of the CBB cycle, respectively. RuBP, ribulose-1,5-bisphosphate; 3PGA, 3-phosphoglycerate; GAP, glyceraldehyde-3-phosphate; DHAP, dihydroxyacetone phosphate; FBP, fructose-1,6-bisphosphate; F6P, fructose-6phosphate; E4P, erythrose-4-phosphate; SBP, sedoheptulose-1,7-bisphosphate; S7P, sedoheptulose-7-phosphate; R5P, ribose-5-phosphate; Xu5P, xylulose-5-phosphate; Ru5P, ribulose-5-phosphate; 6PGN, 6-phosphate gluconate; KDPG, 2-keto-3-deoxy-6-phosphogluconate; G6P, glucose-6-phosphate. RuBisCO, ribulose-1,5-bisphosphate carboxylase/oxygenase; PGK, phosphoglycerate kinase; GAPDH, glyceraldehyde-3phosphate dehydrogenase; TPI, triose phosphate isomerase; FBA, aldolase; FBPase, fructose-1,6-biphosphatase; TK, transketolase; SBPase, sedoheptulose-1,7-biphosphatase; RPI, ribose phosphate isomerase; RPE, ribose phosphate epimerase; PRK, phosphoribulokinase; TAL, transaldolase; EDA, KDPG aldolase; EDD, phosphogluconate dehydratase; GDH, glucose dehydrogenase; GNK, gluconate kinase; GK, glucose kinase; PFK, 6-phosphofructokinase; PGI, phosphoglucose isomerase; TIM, triosephosphate isomerase; GPDH, glucose-6-phosphate dehydrogenase; GNDH, gluconate-6-phosphate dehydrogenase.

\subsection{RuBP carboxylation}

2.1.1 Ribulose-1,5-bisphosphate carboxylase/oxygenase (RuBisCO, EC 4.1.1.39). In the CBB cycle, RuBisCO catalyses the first reaction in the carboxylation stage. This is the predominant way for atmospheric $\mathrm{CO}_{2}$ to enter the biological cycle. RuBisCO is responsible for assimilating $90 \%$ of the carbon found in biomass on Earth. However, RuBisCO is well known as one of the most inefficient enzymes in nature. It cannot distinguish $\mathrm{O}_{2}$ from $\mathrm{CO}_{2}$ and takes one molecule of $\mathrm{O}_{2}$ as the substrate for every four molecules of $\mathrm{CO}_{2}$ fixed. When it uses $\mathrm{O}_{2}$ as the substrate, a process referred to as photorespiration, 2phosphoglycolate, which is toxic to the cell, is produced. To convert 2-phosphoglycolate into nontoxic compounds, ATP is consumed and the fixed carbon is re-released. Thus, the energy conversion and the carbon fixation efficiency of the CBB cycle decreases. However, if the photorespiration pathway is deleted, 
Table 1 Physiological features of plants with deduced CBB cycle enzymes and flux control coefficient of the CBB cycle enzymes under various cultivation conditions

\begin{tabular}{lll}
\hline Enzyme & Organisms & Conditions \\
\hline RuBisCO & Tobacco (Nicotiana tabacum L.) & $\begin{array}{l}15 \mathrm{~h} / 9 \mathrm{~h} \mathrm{light} / \mathrm{dark} \text { cycle }\left(25^{\circ} \mathrm{C} / 20^{\circ} \mathrm{C}\right), \\
300 \mu \mathrm{mol} \text { photons } \mathrm{m}^{-2} \mathrm{~s}^{-1}\end{array}$ \\
& Tobacco (Nicotiana tabacum L.) & $\begin{array}{l}500 \mu \mathrm{mol} \text { photons } \mathrm{m}^{-2} \mathrm{~s}^{-1} \text { irradiance } \\
(12 \mathrm{~h} \mathrm{light} / 12 \mathrm{~h} \mathrm{dark})\end{array}$
\end{tabular}

Tobacco (Nicotiana tabacum L.) $\quad$ Lower than $1000 \mu \mathrm{mol} \mathrm{m} \mathrm{m}^{-2} \mathrm{~s}^{-1}$ irradiance, ambient $\mathrm{CO}_{2}$

Higher than $1500 \mu \mathrm{mol} \mathrm{m}{ }^{-2} \mathrm{~s}^{-1}$ irradiance, ambient $\mathrm{CO}_{2}$ Limited inorganic nitrogen

Tobacco (Nicotiana tabacum L.)

Rice (Oryza sativa L.)

Rice (Oryza sativa L.)

Flaveria bidentis

Tobacco (Nicotiana tabacum)

Arabidopsis thaliana

Flaveria bidentis

Flaveria bidentis

SBPase

Tobacco (Nicotiana tabacum)

Tobacco (Nicotiana tabacum)

Tobacco (Nicotiana tabacum)
$12 \mathrm{~h}$ day/l2 h night cycle (irradiance $340 \mu \mathrm{mol} \mathrm{m}{ }^{-2} \mathrm{~s}^{-1}, 20{ }^{\circ} \mathrm{C}, 65 \%$ relative humidity)

Saturated light conditions

16-22 ${ }^{\circ} \mathrm{C}$ and $28 \mathrm{~Pa}$ intercellular $\mathrm{CO}_{2}$

Day/night growth temperatures were $28 / 15{ }^{\circ} \mathrm{C}$

$1000 \mu \mathrm{mol} \mathrm{m}{ }^{-2} \mathrm{~s}^{-1}, 350$ microbars $\mathrm{CO}_{2}$, and $25^{\circ} \mathrm{C}$

Low $\left(200 \mu \mathrm{mol} \mathrm{m}^{-2} \mathrm{~s}^{-1}\right)$ and high (600 $\left.\mu \mathrm{mol} \mathrm{m} \mathrm{m}^{-2} \mathrm{~s}^{-1}\right)$

28/20 ${ }^{\circ} \mathrm{C}$ day/night temperature, 700 $\mu \mathrm{mol} \mathrm{m}{ }^{-2} \mathrm{~s}^{-1}$, and a $16 \mathrm{~h}$ photoperiod or a naturally lit greenhouse

28/20 ${ }^{\circ} \mathrm{C}$ day/night temperature, 700 $\mu \mathrm{mol} \mathrm{m}{ }^{-2} \mathrm{~s}^{-1}$, and a $16 \mathrm{~h}$ photoperiod or a naturally lit greenhouse

$14 \mathrm{~h} \mathrm{light} / 10 \mathrm{~h}$ dark, $26^{\circ} \mathrm{C} / 18^{\circ} \mathrm{C}, 600-$ $1200 \mu \mathrm{mol} \mathrm{m}{ }^{-2} \mathrm{~s}^{-1}$

Saturated light conditions

Greenhouse in light levels between 400 and $1500 \mu \mathrm{mol} \mathrm{m}^{-2} \mathrm{~s}^{-1}$, a $16 \mathrm{~h}$ photoperiod at a minimum of $25^{\circ} \mathrm{C}$ light $/ 18^{\circ} \mathrm{C}$ dark and a maximum of 35 ${ }^{\circ} \mathrm{C}$ light $/ 25{ }^{\circ} \mathrm{C}$ dark
Effects or flux control coefficient

Reference

Antisense lines (20\% RuBisCO left)

14

have longer senescence phase

Decreased photosynthesis and nitrogen metabolism especially under higher nitrate $(12 \mathrm{mM})$ or ammonium nitrate $(6 \mathrm{mM})$ conditions with less than $60 \%$ RuBisCO left

$>0.2$ flux control coefficient; 0.01-0.03 flux control coefficient with $100 \mu \mathrm{mol}$ $\mathrm{m}^{-2} \mathrm{~s}^{-1}$ irradiance

0.8-0.9 flux control coefficient

0.5 flux control coefficient; photosynthesis was largely reduced while growth was hardly affected Reduced growth and photosynthesis, increased leaf area ratio and increased shoot-to-root ratio when less than $50 \%$ RuBisCO is left Strains with $65 \%$ RuBisCO activity showed a $20 \%$ lower photosynthesis rate in ambient $\mathrm{CO}_{2}$ and a $5 \%$ to $15 \%$ higher photosynthesis rate in 100$115 \mathrm{~Pa} \mathrm{CO}_{2}$

Flux control coefficient $(>0.88)$ detected

With less than $40 \%$ RuBisCO left, $\mathrm{CO}_{2}$ assimilation and photosynthesis was reduced at high light irradiance but unaffected under low light condition (less than $100 \mu \mathrm{mol} \mathrm{m}^{-2} \mathrm{~s}^{-1}$ ) on a wide range of $\mathrm{CO}_{2}$ concentration With $18 \%$ RuBisCO left, soluble protein content reduced the same level as RuBisCO, little change on other photosynthesis proteins. $63 \%$ reduction of $\mathrm{CO}_{2}$ assimilation With 30 to $40 \%$ RuBisCo activity, photosynthesis, growth and above ground biomass are all reduced With $40 \%$ RuBisCO activity left, photosynthesis decreased but the $\mathrm{H}_{2} \mathrm{O}$ exchange rate was similar to that of the wild type

Quantum yield of PSI to PSII, PSI to $\mathrm{CO}_{2}$ fixation and PSII to $\mathrm{CO}_{2}$ fixation increased with enhanced irradiance in the RuBisCO decreased plant With less than $20 \%$ SBPase left, there were no changes in other CBB cycle enzymes but starch accumulation was reduced. With 57\% SBPase left, the $\mathrm{CO}_{2}$ assimilation and quantum yield of PSII reduced

Flux control coefficient: 0.31 under ambient $\mathrm{CO}_{2}$ conditions and 0.54 under saturated $\mathrm{CO}_{2}$ conditions Reduced growth and shoot biomass with $75 \%$ SBPase activity. SBPase decreased resulting in a shorter plant
15 
Table 1 (Contd.)

\begin{tabular}{|c|c|c|c|c|}
\hline Enzyme & Organisms & Conditions & Effects or flux control coefficient & Reference \\
\hline & Tobacco (Nicotiana tabacum L.) & $\begin{array}{l}\text { Greenhouse with a } 14 \mathrm{~h} \text { photoperiod } \\
\text { at } 25^{\circ} \mathrm{C} \text { light } / 18^{\circ} \mathrm{C} \text { dark, } 700 \text { to } 1200 \\
\mu \mathrm{mol} \mathrm{m} \mathrm{m}^{-2} \mathrm{~s}^{-1}\end{array}$ & $\begin{array}{l}-0.2 \text { flux control coefficient in the } \\
\text { youngest developing leaves, } 0.3-0.5 \\
\text { flux control coefficient in mature } \\
\text { leaves, and decreased photosynthesis } \\
\text { and starch accumulation in mature } \\
\text { leaves }\end{array}$ & 28 \\
\hline & Tobacco (Nicotiana tabacum L.) & $\begin{array}{l}\text { Greenhouse } 14 \mathrm{~h} / 10 \mathrm{~h}\left(26^{\circ} \mathrm{C} / 18^{\circ} \mathrm{C}\right) \\
\text { light/dark period, } 1000-1400 \mu \mathrm{mol} \\
\mathrm{m}^{-2} \mathrm{~s}^{-1}\end{array}$ & $\begin{array}{l}\text { Reductions in SBPase activity } \\
\text { between } 9 \% \text { and } 60 \% \text {, maximum } \\
\text { RuBP regeneration capacity declined } \\
\text { linearly }\left(r^{2}=0.79\right) \text { and no significant } \\
\text { change in Rubisco activity }\end{array}$ & 29 \\
\hline & $\begin{array}{l}\text { Rice (Oryza sativa L. ssp. } \\
\text { japonica) }\end{array}$ & $\begin{array}{l}\text { Greenhouse at } 25 \pm 2{ }^{\circ} \mathrm{C} \text { with } \\
\text { a photosynthetic photon flux density } \\
\text { of } 300 \mu \mathrm{mol} \mathrm{m} \mathrm{m}^{-2} \mathrm{~s}^{-1} \text {, a relative } \\
\text { humidity of } 70 \% \text { to } 80 \% \text {, and } \\
\text { a photoperiod of } 14 \mathrm{~h} / 10 \mathrm{~h} \text { light/dark }\end{array}$ & $\begin{array}{l}\text { Stronger effects on reducing growth, } \\
\text { photosynthesis and starch } \\
\text { accumulation under low } \mathrm{N} \text { than high } \\
\mathrm{N} \text { conditions when SBPase was } \\
\text { deduced }\end{array}$ & 30 \\
\hline $\begin{array}{l}\text { Chloroplast } \\
\text { FBPase }\end{array}$ & Potato (Solanum tuberosum) & $\begin{array}{l}16 \mathrm{~h} \mathrm{light}\left(250 \mu \mathrm{mol} \mathrm{m}{ }^{-2} \mathrm{~s}^{-1}, 22^{\circ} \mathrm{C}\right) / 8 \\
\mathrm{~h} \text { dark }\left(15^{\circ} \mathrm{C}\right) \text { under greenhouse } \\
\text { conditions }\end{array}$ & $\begin{array}{l}\text { Unchanged tuber yield and reduced } \\
\text { photosynthetic rate when FBPase } \\
\text { activity decreased to } 36 \% \text { of that of } \\
\text { the wild type. Reduced growth and } \\
\text { photosynthetic rate when FBPase } \\
\text { activity is below } 15 \% \text { of that of the } \\
\text { wild type. }<0.2 \text { flux control coefficient }\end{array}$ & 31 \\
\hline \multirow[t]{4}{*}{ PRK } & Tobacco (Nicotiana tabacum L.) & $\begin{array}{l}330 \mu \mathrm{mol} \text { photons } \mathrm{m}^{-2} \mathrm{~s}^{-1}, 350 \mathrm{ppm} \\
\mathrm{CO}_{2}, 25{ }^{\circ} \mathrm{C}\end{array}$ & $\begin{array}{l}\text { With less than } 85 \% \text { PRK activities left, } \\
\mathrm{CO}_{2} \text { assimilation was reduced. } \\
\text { Almost } 0 \text { flux control coefficient } \\
\text { under low light conditions }\end{array}$ & 32 \\
\hline & Tobacco (Nicotiana tabacum L.) & $\begin{array}{l}330 \mu \mathrm{mol} \text { photons } \mathrm{m}^{-2} \mathrm{~s}^{-1}, 350 \mu \mathrm{mol} \\
\mathrm{CO}_{2} \mathrm{~mol}^{-1}, 25^{\circ} \mathrm{C}\end{array}$ & $\begin{array}{l}94 \% \text { decrease in PRK has stronger } \\
\text { inhibition on photosynthesis (by } \\
35 \% \text { ) with } 0.4 \mathrm{mM} \mathrm{NH}_{4} \mathrm{NO}_{3} \text { than with } \\
0.5 \mathrm{mM} \mathrm{NH}_{4} \mathrm{NO}_{3}(\text { by } 20 \% \text { ) }\end{array}$ & 33 \\
\hline & Tobacco (Nicotiana tabacum L.) & $330 \mu \mathrm{mol}$ photons $\mathrm{m}^{-2} \mathrm{~s}^{-1}$ & $\begin{array}{l}0.25 \text { flux control coefficient to } \mathrm{CO}_{2} \\
\text { assimilation }\end{array}$ & 34 \\
\hline & & $800 \mu \mathrm{mol}$ photons $\mathrm{m}^{-2} \mathrm{~s}^{-1}$ & $\begin{array}{l}0 \text { flux control coefficient to } \mathrm{CO}_{2} \\
\text { assimilation }\end{array}$ & \\
\hline GAPDH & Tobacco (Nicotiana tabacum L.) & Ambient $\mathrm{CO}_{2}$ & 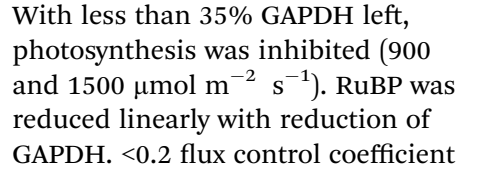 & 35 \\
\hline TK & Tobacco (Nicotiana tabacum L.) & $\begin{array}{l}170 \mu \mathrm{mol} \mathrm{m}{ }^{-2} \mathrm{~s}^{-1}, \text { ambient } \mathrm{CO}_{2} \\
700 \mu \mathrm{mol} \mathrm{m} \\
\text { Saturating light and } \mathrm{s}^{-1}, \text { ambient } \mathrm{CO}_{2}\end{array}$ & $\begin{array}{l}0.07 \text { flux control coefficient } \\
0.32 \text { flux control coefficient } \\
\text { Almost } 1 \text { flux control coefficient }\end{array}$ & 36 \\
\hline \multirow[t]{2}{*}{ FBA } & Potato (Solanum tuberosum) & 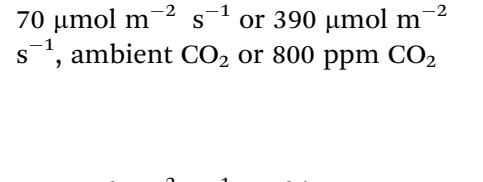 & $\begin{array}{l}\text { Decrease of FBA has stronger } \\
\text { inhibition on photosynthesis and } \\
\text { growth under higher light and } \mathrm{CO}_{2} \\
\text { conditions than lower light and } \mathrm{CO}_{2} \\
\text { conditions }\end{array}$ & 37 \\
\hline & Potato (Solanum tuberosum) & $\begin{array}{l}70 \mu \mathrm{mol} \mathrm{m}^{-2} \mathrm{~s}^{-1} \text {, ambient } \mathrm{CO}_{2} \\
390 \mu \mathrm{mol} \mathrm{m}^{-2} \mathrm{~s}^{-1} \text { light and } 400 \mathrm{ppm} \\
\mathrm{CO}_{2} \\
390 \mu \mathrm{mol} \mathrm{m}^{-2} \mathrm{~s}^{-1} \text { light and } 800 \mathrm{ppm} \\
\mathrm{CO}_{2}\end{array}$ & $\begin{array}{l}0.15 \text { flux control coefficient } \\
0.21 \text { flux control coefficient } \\
0.55 \text { flux control coefficient }\end{array}$ & 38 \\
\hline
\end{tabular}

engineered cyanobacterial strains show a high $\mathrm{CO}_{2}$-requiring phenotype. ${ }^{39}$ One explanation for this is that a high concentration of $\mathrm{CO}_{2}$ decreases the formation of toxic 2-phosphoglycolate. Furthermore, the photorespiration pathway plays a role in balancing the ATP/NADPH ratio and in synthesis of glycine and serine, which means there are physiological benefits for the cell even though photorespiration does decrease the carbon fixation efficiency. ${ }^{39-41}$ Furthermore, the turnover rate for $\mathrm{CO}_{2}$ fixation of RuBisCO is only 1-10 $\mathrm{s}^{-1}$. From an evolutionary aspect, there are some clues to the low efficiency of RuBisCO. RuBisCO started to evolve about 3.8 billion years ago, even before the appearance of cyanobacteria and the CBB cycle. At 
that time, RuBisCO's substrate $\mathrm{CO}_{2}$ was the dominant atmospheric gas and there was no $\mathrm{O}_{2}$ in the air. Therefore, photorespiration was not an issue. However, RuBisCO failed to evolve into a more efficient enzyme, regardless the appearance and increasing concentration of atmospheric $\mathrm{O}_{2}$. This may be due to the balance between biochemical constraint and evolutionary pressure, ${ }^{42}$ carboxylation velocity and $\mathrm{CO}_{2}$ affinity, ${ }^{43}$ and holoenzyme stability and activity. ${ }^{44}$ Even though there has been no experimental breakthrough on modifying RuBisCO for obtaining e.g. a faster turnover rate and higher $\mathrm{CO}_{2}$ affinity simultaneously so far, computer-based modelling has shown that it is possible to improve RuBisCO specificity and the turnover rate simultaneously. ${ }^{45}$ Actually, engineered RuBisCO with an enhanced turnover rate without affecting $\mathrm{CO}_{2}$ affinity was reported in Synechocystis PCC 6803 and E. coli. ${ }^{46}$ One of the engineered Synechocystis PCC 6803 strains $\left(\mathrm{Rbc}^{\mathrm{F140I}}\right)$ showed a faster photosynthetic rate than wild-type cells.

Photoautotrophic organisms have developed other strategies to deal with the issue of the changed atmospheric ratio of $\mathrm{CO}_{2}$ and $\mathrm{O}_{2}$, adapted to different habitation conditions. Green algae and cyanobacteria have developed special carbon concentrating mechanisms, pyrenoids in green algae and carboxysomes in cyanobacteria, to increase the $\mathrm{CO}_{2}$ concentration near RuBisCO. Pyrenoids are also found in hornworts. ${ }^{47,48}$ In $\mathrm{C} 4$ and crassulacean acid metabolism (CAM) plants, the carbon fixation process uses the relatively more efficient carboxylase phosphoenolpyruvate carboxylase (PEPc) to fix atmospheric $\mathrm{CO}_{2}$ into a $\mathrm{C} 4$ acid. This $\mathrm{C} 4$ acid then in a later step undergoes decarboxylation to release $\mathrm{CO}_{2}$ near RuBisCO, resulting in a high concentration of $\mathrm{CO}_{2}$ in the vicinity of the enzyme. In another word, the initial $\mathrm{CO}_{2}$-fixation step is separated from the RuBisCO step either in space, as is the case of $\mathrm{C} 4$ plants with different cell types, or in time, as in CAM plants where the reactions take place at different phases of the day/night cycles. ${ }^{49}$ In contrast, C3 plants do not have similar compartments or mechanisms to concentrate $\mathrm{CO}_{2}$. They instead contain a very high concentration of RuBisCO, about a quarter of the soluble proteins in leaves, consuming almost half of the available nitrogen in the cells, to compensate for the low catalytic performance.

Due to the adaption to different growth environments and available $\mathrm{CO}_{2}$ concentrations in cells, RuBisCO enzymes purified from different sources have varied carboxylation velocity and $\mathrm{CO}_{2}$ affinity (Fig. 2). For instance, RuBisCO in C3 plants (without carbon-concentrating mechanisms) has relatively higher $\mathrm{CO}_{2}$ affinity and a lower carboxylation velocity compared to RuBisCO in organisms with carbon-concentrating mechanisms (C4 plants, CAM plants, hornworts, green algae and cyanobacteria). ${ }^{50}$ Since the kinetic parameters are so different, heterologous RuBisCO expression will be a promising strategy to improve RuBisCO performance and to increase the carbon fixation efficiency, for example, introducing a higher $\mathrm{CO}_{2}$ affinity RuBisCO into cyanobacteria. However, RuBisCO folding and assembly are complex processes involving chaperons that vary between species. ${ }^{51,52}$ Therefore, this strategy is highly restricted. ${ }^{53}$ In one example, a functional RuBisCO from Synechococcus elongatus PCC 7942 was heterologously expressed in tobacco. Even though the transformed lines could only grow autotrophically at an elevated $\mathrm{CO}_{2}$ concentration $\left(3 \% \mathrm{CO}_{2}\right)$, the $\mathrm{CO}_{2}$ fixation rate per RuBisCO protein was significantly increased. ${ }^{54}$ Later, it was further demonstrated that co-expression of the chaperone RbcX or the carboxysome protein CcmM35 from Synechococcus elongatus PCC 7942 was not essential for a functional cyanobacterial RuBisCO in tobacco. ${ }^{55}$ This indicates that Synechococcus elongatus PCC 7942 RuBisCO is able to fold and assemble properly with tobacco chaperons. In contrast, RuBisCO from the rhodophyte Galdieria sulphuraria and the diatom Phaeodactylum tricornutum failed to fold and assemble into functional enzymes in tobacco plants. ${ }^{53}$ This may be mainly due to the incompatibility of RuBisCO with the assembly chaperon $\mathrm{RbcX}$, since $\mathrm{RbcX}$ requires specific interactions with its corresponding RuBisCO and acts as a gatekeeper for formation of the holoenzyme. In contrast, folding chaperons are nonspecific and did not show negative effects on mutated RuBisCO. ${ }^{46}$ Synechococcus elongatus PCC 7942 is evolutionarily closer to tobacco than the other two species. This indicates that choosing a more closely related RuBisCO to transfer to host cells may be beneficial. Following this line, heterologous expression of RuBisCO in the same groups e.g. from cyanobacteria to cyanobacteria is a strategy worth trying. Many studies have shown positive effects on target bioproduct formation using this strategy in host cells (Table 2). For example, overexpressing Synechococcus elongatus PCC 6301 RuBisCO in the very closely related strain Synechococcus elongatus PCC 7942 resulted in increased RuBisCO activity and

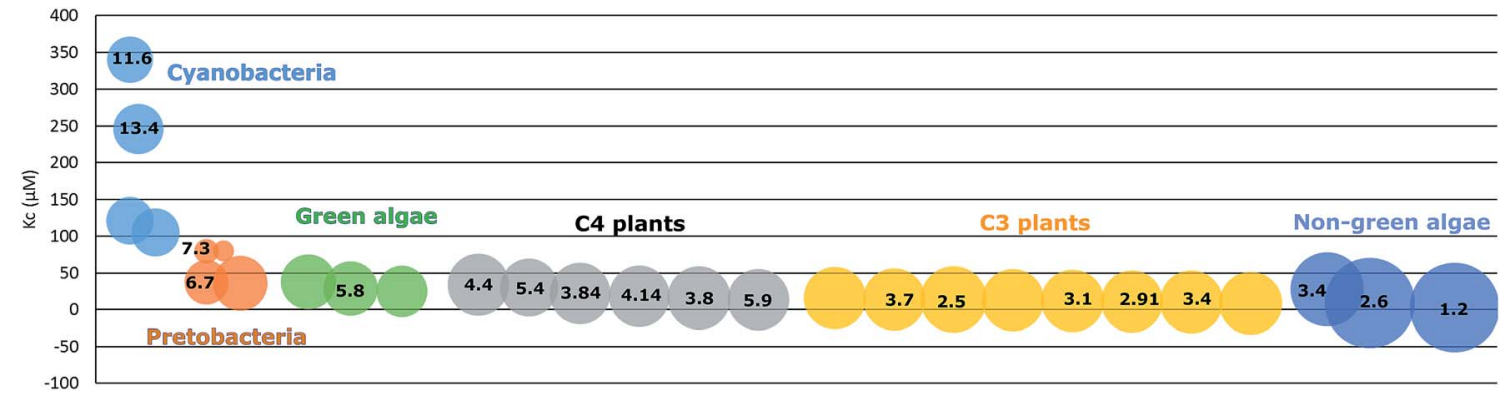

Fig. 2 Variation of RuBisCO kinetics. The size of an individual circle represents specificity $S\left(K_{\circ} V_{c} / K_{c} V_{o}\right)$, ranging from 9 to $167 . K_{c}$ and $K_{\circ}$ represent $\mathrm{CO}_{2}$ and $\mathrm{O}_{2}$ affinity, respectively. $V_{c}$ and $V_{\mathrm{o}}$ indicate the catalytic rate of carboxylation and oxygenation, respectively. The number in the individual circle represent $V_{c}\left(S^{-1}\right)$ (modified from Savir et al. 2010). 
isobutyraldehyde production. ${ }^{56}$ Heterologous expression may avoid some of the negative regulations of protein expression and/or activity, but at the same time still use the chaperones of the host cells to fold and assemble into a functional enzyme.

2.1.2 Carbon-concentrating mechanisms. Another obvious obstacle to increase RuBisCO performance is the low concentration of $\mathrm{CO}_{2}$ near RuBisCO. A direct method targeting this problem is to supply $\mathrm{CO}_{2}$ or $\mathrm{NaHCO}_{3}$ to the culture. Another promising method is engineering carbon-concentrating mechanisms. Increasing in vivo $\mathrm{CO}_{2}$ concentration may increase RuBisCO carbon fixation for two reasons: (i) allowing the carboxylation rate to be close to the maximum turnover rate; (ii) reducing photorespiration.

In cyanobacteria, carbon-concentrating mechanisms include the inorganic carbon transporters (of $\mathrm{CO}_{2}$ and $\mathrm{HCO}_{3}{ }^{-}$) and the special compartment named carboxysome. There are five inorganic carbon transporters in cyanobacteria; BCT1, SbtA, BicA, $\mathrm{NDH}-\mathrm{I}_{4}$ and $\mathrm{NDH}-\mathrm{I}_{3}$. The five transporters are different in expression, substrate affinity, and location ${ }^{57}$ (Table 3). Among the five inorganic transporters, native BicA has been overexpressed in Synechocystis PCC 6803. It was found that in the engineered strains, the growth rate was two times faster than that of the wild-type strain, and a higher amount of biomass was accumulated. ${ }^{58}$ When supplied with a higher $\mathrm{CO}_{2}$ concentration $(0.5 \%)$, growth of the BicA-overexpressing strains was further enhanced. This means that under atmospheric $\mathrm{CO}_{2}$ conditions, the growth was still restricted by the carbon concentration even though BicA was overexpressed. This may be due to the low $\mathrm{CO}_{2}$ affinity of BicA. ${ }^{58}$ Therefore, overexpressing higher $\mathrm{CO}_{2}$ affinity transporters may be a better way to increase growth under ambient $\mathrm{CO}_{2}$ conditions. However, each of the other four transporters is encoded by a long operon consisting of several genes, increasing the cloning difficulties. Another promising strategy is to change low Ci induced transporters, like SbtA, BCT1 and $\mathrm{NDH}-\mathrm{I}_{3}$, into constitutively expressed transporters. This does not only involve controlling the transcription of the corresponding genes, but may also be related to translation and/or post-translation modifications, depending on the induction mechanisms.

In cyanobacteria, another crucial parameter in the carbonconcentrating mechanism is the special micro-compartment called carboxysome. ${ }^{59}$ Carboxysomes encapsulate RuBisCO and carbonic anhydrase. Carbonic anhydrase converts bicarbonate into $\mathrm{CO}_{2}$, leading to an order of magnitude enhanced $\mathrm{CO}_{2}$ concentration near RuBisCO. Since C3 plants do not have similar compartments, transplanting carboxysomes or compartments with similar functions into C3 plants is regarded as one potential way to increase carbon fixation and plant productivity. Cyanobacteria have two types of carboxysomes, $\alpha$ and $\beta$ carboxysomes, encapsulating form $1 \mathrm{~A}$ and $1 \mathrm{~B}$ RuBisCOs, respectively. Since plants have form $1 \mathrm{~B}$ RuBisCO, it would make sense to attempt transplanting $\beta$ carboxysomes into plants. Even though there are reports of successfully assembling carboxysomes in E. coli cells, ${ }^{60}$ doing the same thing in plant chloroplasts is still challenging given the higher complexity of an eukaryotic cell. The assembly process of $\beta$ carboxysomes in Synechococcus elongatus PCC 7942 has been elucidated, increasing the chance to engineer a functional carboxysome in foreign cells. ${ }^{61}$ Functional carboxysomes with truncated proteins have also been reported. ${ }^{62}$ This work benefits carboxysome transplanting, since shorter and/or fewer genes are required for a functional carboxysome in this case. A smaller carboxysome will also conserve carbon, nitrogen and other resources for other usages in the cell. Carbonic anhydrases also localize differently in plants and cyanobacteria, in the cytosol in plants and in the carboxysome in cyanobacteria. Therefore, how to direct a cytosolic carbonic anhydrase into a carboxysome is another issue. One possible strategy is to inactivate or delete the native cytosolic carbonic anhydrase and at the same time express a carboxysome carbonic anhydrase together with the carboxysome.

2.1.3 RuBisCO activase. RuBisCO has a complicated catalytic process. Both carboxylation and oxygenation start with the carboxylation of a specific lysine in the $\mathrm{N}$-terminal domain by a non-substrate $\mathrm{CO}_{2}$ (carbamylation) followed by $\mathrm{Mg}^{2+}$ binding to stabilize the protein. Then, RuBP binds to the active site and is enolized to an enediol, followed by the structural change of loop 6 and the flexible tail of the C-terminal domain. At this point, the active site is ready to bind the substrate $\mathrm{CO}_{2}$ or $\mathrm{O}_{2}$. During the multi-step catalytic process, RuBisCO is inhibited by sugar phosphates, like the substrate RuBP, and 2-carboxy-Darabinitol-1-phosphate (CA1P, night-time inhibitor of RuBisCO in plants). To release the inhibitors and to reactivate RuBisCO, an AAA+ (ATPase associated with various cellular activities) protein, RuBisCO activase (Rca), is required. Rca exists in a hexameric form, changes RuBisCO active site structures and releases the inhibitors at the expense of ATP. ${ }^{63}$ It has been reported that Rca repairs one active site at one time with minimal structural perturbation. ${ }^{64}$ Even though studies of Rca in plants began in the 1980s, knowledge of Rca in cyanobacteria is limited. Until now, Rca has been found in some heterocystous Anabaena strains, but not in any unicellular or non-heterocystous cyanobacteria, even though cell extracts of Synechococcus elongatus PCC 7942 were reported to cross-react with antibodies raised against RuBisCO activase..$^{65}$ Therefore, Rca may not be an essential factor to maintain an active cyanobacterial RuBisCO in unicellular cyanobacteria. If this is the case, this means that some cyanobacterial RuBisCO does not require Rca for reactivation, and thus transplanting these cyanobacterial RuBisCOs into plant cells may not require expression of Rca in those cells.

\subsection{3-Phosphoglycerate (PGA) reduction}

Two enzymes are involved in the process of PGA reduction, a phosphoglycerate kinase (PGK, EC 2.7.2.3) and glyceraldehyde-3-phosphate dehydrogenase (GAPDH, EC 1.2.1.13). In the CBB cycle, NADPH and two thirds of the ATP used in the CBB cycle are consumed in these two steps. The product of this process, glyceraldehyde-3-phosphate (GAP), is one of the main outputs of the CBB cycle. In the cyanobacterial model strain Synechocystis PCC 6803, there are two types of GAPDH, GAPDH1 and GAPDH2, encoded by gap1 and gap2, respectively. ${ }^{66}$ GAPDH2 catalyses the reaction in the CBB cycle and is redox regulated through associating and dissociating with the small 
Table 2 Effects of overexpressing the CBB cycle enzymes in cyanobacteria and plants reported in the literature

\begin{tabular}{|c|c|c|c|c|}
\hline Enzyme & Host & Source & Main effects & Reference \\
\hline \multirow[t]{9}{*}{ RuBisCO } & Synechococcus elongatus PCC 7942 & Allochromatium vinosum & $\begin{array}{l}1.5 \text { to } 4 \text { fold increase of RuBisCO activity; } \\
1.6 \text { times higher total photosynthesis } \\
\text { activity }\end{array}$ & 77 \\
\hline & Synechococcus elongatus PCC 7942 & $\begin{array}{l}\text { Synechococcus elongatus PCC } \\
6301\end{array}$ & $\begin{array}{l}1.4 \text { fold increase in total RuBisCO } \\
\text { activity; unchanged photosynthetic } \mathrm{O}_{2} \\
\text { production; } 2 \text { fold higher } \\
\text { isobutyraldehyde production }\end{array}$ & 56 \\
\hline & Synechococcus elongatus PCC 7942 & Synechococcus elongatus 7942 & $\begin{array}{l}\text { Unchanged oxygen evolution and free } \\
\text { fatty acid production }\end{array}$ & 78 \\
\hline & Synechococcus PCC 7002 & $\begin{array}{l}\text { Synechococcus elongatus PCC } \\
7942\end{array}$ & $\begin{array}{l}3 \text { fold increase of free fatty acid } \\
\text { production }\end{array}$ & 79 \\
\hline & Tobacco, Nicotiana tabacum & $\begin{array}{l}\text { Synechococcus elongatus PCC } \\
7942\end{array}$ & $\begin{array}{l}\text { Higher rates of } \mathrm{CO}_{2} \text { fixation per unit of } \\
\text { enzyme, autotrophic growth only rely on } \\
\text { the cyanobacterial RuBisCO under } 3 \% \\
\mathrm{CO}_{2} \text { conditions }\end{array}$ & 54 \\
\hline & Synechococcus elongatus PCC 7942 & Synechococcus PCC 7002 & $\begin{array}{l}\text { Positive effects on growth and } 2,3- \\
\text { butanediol production using } 10 \mathrm{~g} \mathrm{~L}^{-1} \\
\text { glucose in the BG11 medium when } \\
\text { cooverexpressed with PRK and OPP } \\
\text { enzymes, and the galactose transporter }\end{array}$ & 80 \\
\hline & Synechococcus elongatus PCC 7942 & $\begin{array}{l}\text { Synechococcus elongatus PCC } \\
7942\end{array}$ & $\begin{array}{l}\text { No significant effects on growth and 2,3- } \\
\text { butanediol production using } 10 \mathrm{~g} \mathrm{~L}^{-1} \\
\text { glucose in the BG11 medium }\end{array}$ & 80 \\
\hline & Synechocystis PCC 6803 & Synechocystis PCC 6803 & $\begin{array}{l}\text { Increased RuBisCO content when the } \\
\text { FLAG tag or } c c m M \text { gene was used; } \\
\text { increased growth, biomass accumulation } \\
\text { and oxygen evolution under } 100 \mu \mathrm{mol} \\
\text { photons } \mathrm{m}^{-2} \mathrm{~s}^{-1} \text { light intensity; } \\
\text { increased ethanol production with air }\end{array}$ & 81,82 \\
\hline & Synechococcus PCC 7002 & Synechococcus PCC 7002 & $\begin{array}{l}\text { No impact on growth and } \mathrm{O}_{2} \text { evolution, } \\
\text { increased protein content of pyruvate } \\
\text { metabolism and fatty acid biosynthesis }\end{array}$ & 83 \\
\hline \multirow[t]{2}{*}{$\begin{array}{l}\text { Chloroplastic } \\
\text { FBPase }\end{array}$} & Anabaena PCC 7120 & Wheat & $\begin{array}{l}1.4 \text { fold higher FBPase activity, increased } \\
\text { net photosynthesis }(117.2 \%) \text { and true } \\
\text { photosynthesis }(122.5 \%) \text {, faster growth } \\
\text { and more chlorophyll a under } \\
\text { atmospheric conditions }\left(360 \mu \mathrm{mol} \mathrm{mol}^{-1}\right. \\
\left.\mathrm{CO}_{2}\right)\end{array}$ & 84 \\
\hline & Chlamydomonas reinhardtii & Chlamydomonas reinhardtii & $\begin{array}{l}1.4 \text { fold higher FBPase activity and slower } \\
\text { photoautotrophic growth with or without } \\
\text { elevated } \mathrm{CO}_{2} \text { levels }\end{array}$ & 85 \\
\hline Form II FBPase & $\begin{array}{l}\text { Tobacco, Nicotiana tabacum } \mathrm{cv} . \\
\text { Xanthi }\end{array}$ & $\begin{array}{l}\text { Synechococcus elongatus PCC } \\
7942\end{array}$ & $\begin{array}{l}\text { Transformant line with } 2.3 \text { fold higher } \\
\text { FBPase activity had higher dry matter } \\
\text { under atmospheric conditions, } \\
\text { photosynthetic activity at saturated light } \\
\text { intensity, RuBP level, in vivo RuBisCO } \\
\text { activation state, and hexose, sucrose and } \\
\text { starch concentrations in upper and lower } \\
\text { leaves }\end{array}$ & 86 \\
\hline \multirow[t]{2}{*}{ FBP/SBPase } & Tobacco & $\begin{array}{l}\text { Synechococcus elongatus PCC } \\
7942\end{array}$ & $\begin{array}{l}\text { Increased photosynthetic } \mathrm{CO}_{2} \text { fixation, } \\
\text { photosynthesis, growth, RuBP and GAP } \\
\text { concentrations, initial RuBisCO activity } \\
\text { (probably due to the higher RuBP } \\
\text { concentration) under atmospheric } \\
\text { conditions }\end{array}$ & 87 \\
\hline & Euglena gracilis & $\begin{array}{l}\text { Synechococcus elongatus PCC } \\
7942\end{array}$ & $\begin{array}{l}\text { Larger cell volume at } 100 \mu \mathrm{mol} \text { photons } \\
\mathrm{m}^{-2} \mathrm{~s}^{-1} \text { and } 0.04 \% \mathrm{CO}_{2} \text {, enhanced } \\
\text { biomass and photosynthetic activity } \\
\text { under high light and high } \mathrm{CO}_{2} \\
\text { conditions, increased wax ester } \\
\text { production on anaerobiosis }\end{array}$ & 88 \\
\hline
\end{tabular}


Table 2 (Contd.)

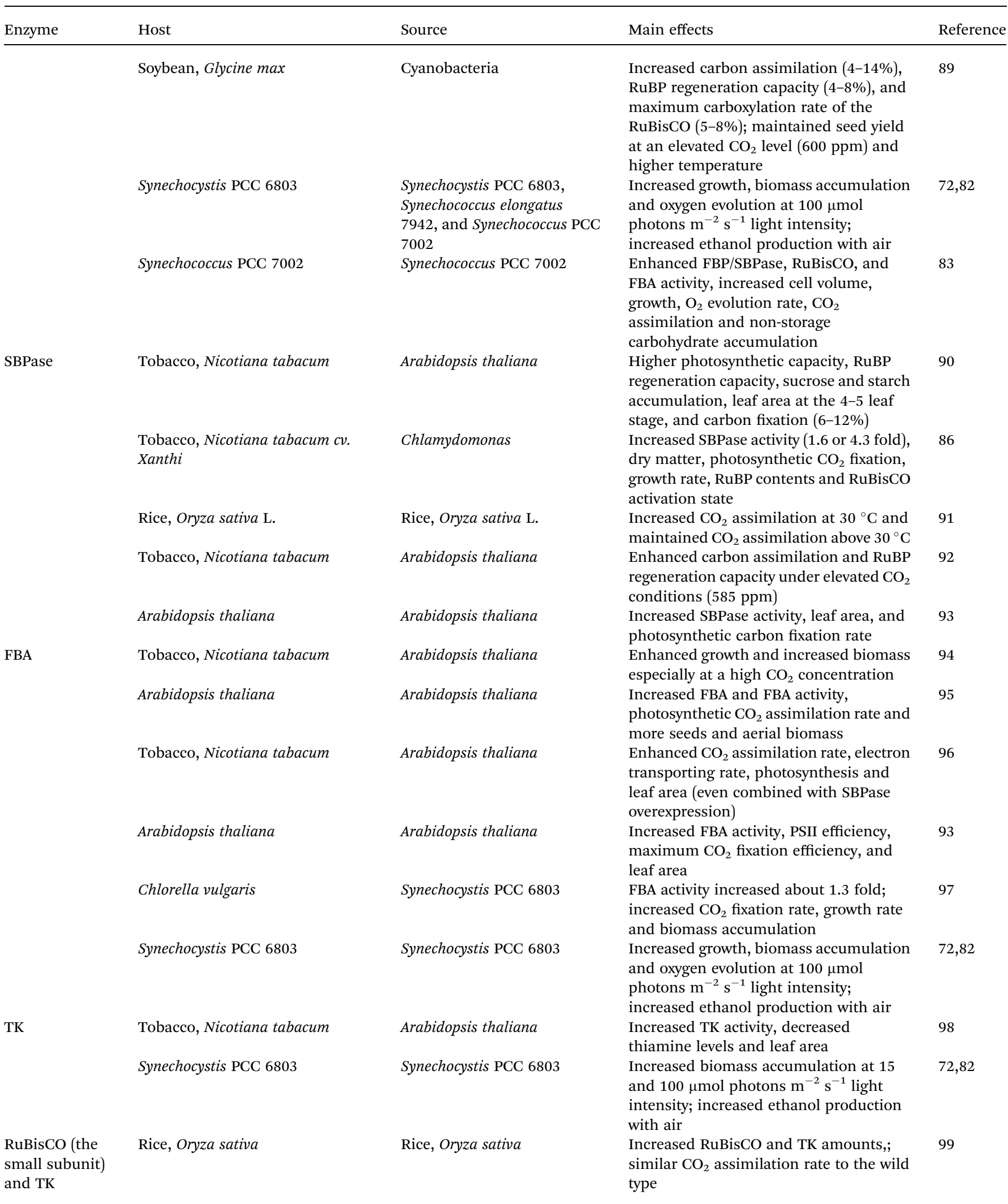

redox-sensitive protein CP12 and phosphoribulokinase (PRK, EC 2.7.1.19). ${ }^{67}$ The three proteins form a complex when the $\mathrm{NAD}(\mathrm{P}) \mathrm{H}$ level is low (for example in darkness).${ }^{67}$ Formation of the complex is essential, specifically in mixotrophic growth or light/dark cycles due to the competition between the CBB cycle and OPP pathway. Ribulose-5-phosphate is an intermediate in 
both the CBB cycle (substrate of PRK) and the OPP pathway (substrate of ribulose-5-phosphate epimerase/isomerase). This means that PRK competes for ribulose-5-phosphate with ribulose-5-phosphate epimerase/isomerase. In darkness, cyanobacteria rely on the OPP pathway to generate reducing equivalents (mainly NADPH). If the OPP pathway is inhibited in darkness (by PRK assimilating ribulose-5-phosphate in this case), there will not be enough reducing equivalents and cell growth will be hampered. However, it is not the same situation when cells are grown in continuous light, since the photochemical phases will supply cells with enough NADPH. Therefore, the role of GAPDH should attract attention, especially when cells are exposed to light/dark cycles. However, in anti-sense tobacco plants with reduced levels of chloroplast GAPDH, carbon assimilation under ambient conditions was not inhibited unless less than $30-40 \%$ of the wild-type GAPDH activity was left. ${ }^{35}$ This means that GAPDH does not have a significant flux control co-efficient for the CBB cycle.

\subsection{Ribulose-1,5-biphosphate (RuBP) regeneration}

As discussed above, there are 11 enzymes in the CBB cycle and most of them are in the stage called "RuBP regeneration". This stage is crucial to maintain the carbon fixation rate especially under relatively low light conditions. This concept was first suggested in the 1980s, from a CBB cycle model of C3 plants. ${ }^{68}$ In this stage, the last reaction, catalysed by PRK, consumes the remaining one-third of the ATP used in the whole CBB cycle. Interestingly, reducing the expression levels of PRK in antisense tobacco plants did not affect carbon assimilation and growth until the activity of PRK was decreased by more than $85 \%{ }^{32}$ even though it catalyses an irreversible reaction. This indicates only minor control on the carbon flux by PRK.

Three enzymes which have been reported to play important roles in controlling the $\mathrm{CBB}$ cycle flux are aldolase, fructose1,6/sedoheptulose-1,7-biphosphatase and transketolase. ${ }^{69,70}$ Aldolase (FBA, EC 4.1.2.13) catalyses the aldol condensation of dihydroxyacetone phosphate (DHAP) and GAP to fructose-1,6bisphosphate (FBP) or DHAP and erythrose-4-phosphate (E4P) into sedoheptulose-1,7-bisphosphate (SBP) in the CBB cycle. Since SBP is not an OPP pathway intermediate, one can say that FBA catalyses a reversible reaction between FBP and DHAP and GAP and an irreversible reaction between SBP and DHAP and E4P. There are two classes (I and II) of FBA, defined based on the catalytic mechanisms and distributions in the biosphere. Their respective genes do not show DNA sequence homology, which implies separate evolution paths. Class II FBA catalyses reactions in the CBB cycle in both Synechocystis PCC 6803 and plants. The function of class II FBA cannot be replaced by class I FBA in Synechocystis PCC 6803 under autotrophic growth conditions, indicating that class I FBA is not able to catalyse the reactions in the CBB cycle. ${ }^{71}$

Early studies of FBA in controlling photosynthesis and growth of potato plants showed that reduction of plastid FBA activity by more than $30 \%$ inhibits photosynthesis under $400 \mu \mathrm{mol}$ photons $\mathrm{m}^{-2} \mathrm{~s}^{-1}$ irradiance and ambient carbon conditions. ${ }^{37,38}$ The slow regeneration of RuBP is responsible for the phenomenon. Activities of plastid FBPase and PRK are also reduced in FBA antisense potato lines. These results indicate that even though FBA catalyses reversible reactions, it has significant control over the CBB cycle carbon flux. This is further confirmed in other plants, microalgae and cyanobacteria (Table 2). When class II FBA is overexpressed, growth, biomass accumulation, and/or $\mathrm{CO}_{2}$ assimilation are increased under certain growth conditions. Recently, a report showed that overexpressing FBA in engineered Synechocystis PCC 6803 increases the production of ethanol. ${ }^{72}$

The next metabolic steps in the CBB cycle after FBA are catalyzed by plastid FBPase (EC 3.1.3.12), dephosphorylating FBP into fructose-6-phosphate (F6P) and SBPase (EC 3.1.3.37), and dephosphorylating SBP into sedoheptulose-7-phosphate (S7P) in plants. Plastid FBPase and SBPase have very different evolutionary origins. Plastid FBPase originated from bacteria and was transferred into plant chloroplasts by endosymbiosis, while SBPase originated from archaea. ${ }^{11}$ Regardless of the different evolution paths, the two enzymes share high structural homology, with differences only on the solvent-exposed surface area. Plant SBPase and most plastid FBPases, except some later emerging plastid FBPases in land plants, ${ }^{73}$ contain the redox regulation target, cysteine. ${ }^{74}$ The major redox regulator is thioredoxin $f$, which is reduced by ferredoxin. Therefore, the activities of FBPase and SBPase are regulated by light. They are also inhibited by glycerate. ${ }^{75}$ These regulatory mechanisms allow dedicated regulation of plastid FBPase and SBPase. In cyanobacteria, the bi-functional enzyme FBP/SBPase plays the same role as plastid FBPase and SBPase. However, cyanobacterial FBP/SBPase does not share amino acid homology with plant plastid FBPase and SBPase. Therefore, existence and mechanisms of the redox-regulations, if there are any, of cyanobacterial $\mathrm{FBP} / \mathrm{SBP}$ ase are unclear.

Products of FBPase and SBPase are points where carbon leaves the CBB cycle in the form of carbohydrate. This makes these enzymes important in keeping the input and output of the CBB cycle balanced. A C3 plant model shows that the plastid FBPase and SBPase contents are very low compared to levels of other CBB cycle enzymes. ${ }^{68}$ Concentrations of most of the CBB cycle enzymes are higher than those of their corresponding substrates, while FBPase and SBPase are present in similar concentrations to their substrates in Chlamydomonas reinhardtii. ${ }^{76}$ It has been shown that dramatic reduction of the levels of plastid FBPase in potato (less than 15\% activity remained) and SBPase in tobacco (less than $20 \%$ activity remained) have negative effects on plant growth. ${ }^{25,31}$

To summarize, plastid FBPase and SBPase are redox regulated, catalyse irreversible reactions, and occur at low levels compared to the other CBB cycle enzymes, and these reduced levels result in growth deficiencies. Therefore, plastid FBPase and SBPase may be crucial enzymes in controlling the carbon flux through the CBB cycle, maybe by affecting the RuBP regeneration. Furthermore, there are plenty of experimental reports where increasing FBPase and/or SBPase through genetic engineering in plants, algae or cyanobacteria led to enhanced growth and/or photosynthesis (Table 2). In Synechocystis PCC 6803 , increasing the content of $\mathrm{FBP} / \mathrm{SBPase}$, either a native or 
Table 3 Inorganic carbon transporters in cyanobacteria

\begin{tabular}{|c|c|c|c|c|}
\hline BCT1 & Traffic ATPase, $\mathrm{HCO}_{3}{ }^{-}$ & $\begin{array}{l}\text { Induced under Ci limited } \\
\text { conditions, enhanced } \\
\text { transcription under high } \\
\text { light }\end{array}$ & $\begin{array}{l}\text { High affinity ( } 5 \mu \mathrm{M} \\
\text { Synechococcus elongatus } \text { PCC } \\
7942 \text { BCT1); medium to low } \\
\text { flux rate }\end{array}$ & Plasma membrane \\
\hline SbtA & $\begin{array}{l}\mathrm{Na}^{+} \text {-dependent } \mathrm{HCO}_{3}{ }^{-} \\
\text {transporter }\end{array}$ & $\begin{array}{l}\text { Induced under Ci limited } \\
\text { conditions }\end{array}$ & $\begin{array}{l}\text { High affinity ( } 2 \mu \mathrm{M} \\
\text { Synechococcus } \text { PCC } 7002 \\
\text { SbtA); low flux rate }\end{array}$ & Plasma membrane \\
\hline $\mathrm{NDH}-\mathrm{I}_{4}$ & $\mathrm{CO}_{2}$ uptake & Constitutively expressed & $\begin{array}{l}\text { Relatively high affinity }(\approx 10 \\
\mu \mathrm{M})\end{array}$ & Plasma membrane \\
\hline
\end{tabular}

a non-native version, resulted in increased ethanol production in the engineered strains (Table 2).

The next step in regeneration of RuBP is catalysed by transketolase (TK, EC 2.2.1.1). In general, reactions catalysed by transketolase are reversible. It uses GAP and S7P to produce xylulose-5-phosphate (Xu5P) and ribose-5-phosphate (R5P), or GAP and F6P to produce Xu5P and erythrose 4-phosphate (E4P). Activation of TK requires the cofactor thiamine diphosphate (TPP), the active form of thiamine (vitamin B1). The synthesis of TPP in turn requires GAP and R5P as substrates. Therefore, there may be some circuit regulation on TK activity and TPP levels. E4P is also one of the precursors of the shikimic acid pathway, which is one of the connections between central and secondary carbon metabolisms. Thus, TK is another branch point where fixed carbon leaves the CBB cycle. The indirect regulation by its own product (R5P) and substrate (GAP) and the role in connecting the secondary metabolism to the central carbon metabolism make TK one of the key enzymes in controlling the carbon flux through the CBB cycle. In tobacco anti-sense plants, a $20 \%$ reduction of TK activity resulted in decreased photosynthesis and growth. Formation of aromatic amino acids and the phenylpropanoid metabolism pathway are also inhibited. ${ }^{36}$ Under saturated light $(700 \mu \mathrm{mol}$ photons $\mathrm{m}^{-2} \mathrm{~s}^{-1}$ ) and $\mathrm{CO}_{2}(5000 \mathrm{ppm})$ conditions, it was found that TK had full control over the maximum photosynthesis rate, meaning that photosynthesis was linear with TK activity under these conditions. In contrast, RuBisCO does not exert any control over the carbon flux under these conditions. Even though it is unexpected that TK would have a strong control over the CBB cycle carbon flux since it catalyses reversible reactions and is regarded as a non-finely regulated enzyme, positive effects on carbohydrate accumulation, leaf size or end product yield are observed by overexpressing this enzyme (Table 2).

\section{Alternative carbon fixation cycles}

Organisms that utilize $\mathrm{CO}_{2}$ (or $\mathrm{HCO}_{3}{ }^{-}$) as the sole carbon source are defined as autotrophic organisms. The energy source of autotrophic organisms can be solar energy (like cyanobacteria and plants, photoautotrophs) or chemical energy (chemolithoautotrophs). The CBB cycle is found in most photoautotrophs. Since efforts at optimizing RuBisCO performance and improving the CBB cycle efficiency have shown only limited success, interest has been redirected towards other carbon fixation cycles and carboxylases. Alternative carbon fixation cycles found in archaea include the reductive acetyl-CoA cycle, the reductive TCA (rTCA) cycle, the 3-hydroxypropionate (3-HP) cycle, and the 4-hydroxybutyrate cycles (3-hydroxypropionate/ 4-hydroxybutyrate, 3-HP/4-HB cycle, and dicarboxylate-4hydroxybutyrate, DC/4-HB cycle ${ }^{\mathbf{1 0 0}}$ ) (Table 4). In some archaea, there is form III RuBisCO. However, form III RuBisCO does not support autotrophic growth and no complete CBB cycle has been found in these archaea.

One standard to evaluate carbon fixation cycles is the carbon fixation efficiency, which is mainly estimated from reaction kinetics and ATP requirements. ATP requirements in a carbon fixation cycle are largely affected by the carbon fixation enzyme(s). ${ }^{101}$ Some carboxylases directly or indirectly catalyse the assimilation of $\mathrm{CO}_{2}$ associated with ATP hydrolysis. For example, in the $\mathrm{CBB}$ cycle, the $\mathrm{CO}_{2}$ assimilation using RuBisCO is associated with ATP usage in the step catalysed by phosphoglycerate kinase. In contrast, $\alpha$-ketoglutarate:ferredoxin oxidoreductase in the reductive TCA cycle assimilates $\mathrm{CO}_{2}$ associated with reduction of ferredoxin. This will reduce the overall ATP requirement in the cycle. Therefore, to synthesize one molecule of acetyl-CoA, 7 versus 2 ATPs are required in the CBB cycle and the reductive TCA cycle. ${ }^{102}$ Among all the native cycles, the reductive acetyl-CoA pathway is special in respect to the carbon fixation reactions. In the reductive acetyl-CoA pathway, five sixths of the carbon is assimilated by formate dehydrogenase and CO dehydrogenase/acetyl-CoA synthase. Therefore, the carbon assimilation in this cycle is more reduction dependent, which makes this cycle more energy efficient, and it is predicted to have a higher biomass yield. ${ }^{103}$ In general, the ATP efficient cycles are naturally found under anaerobic conditions while aerobic archaea usually have the ATP 
Table 4 Native biological carbon fixation cycles with individual specific carbon assimilation enzyme(s)

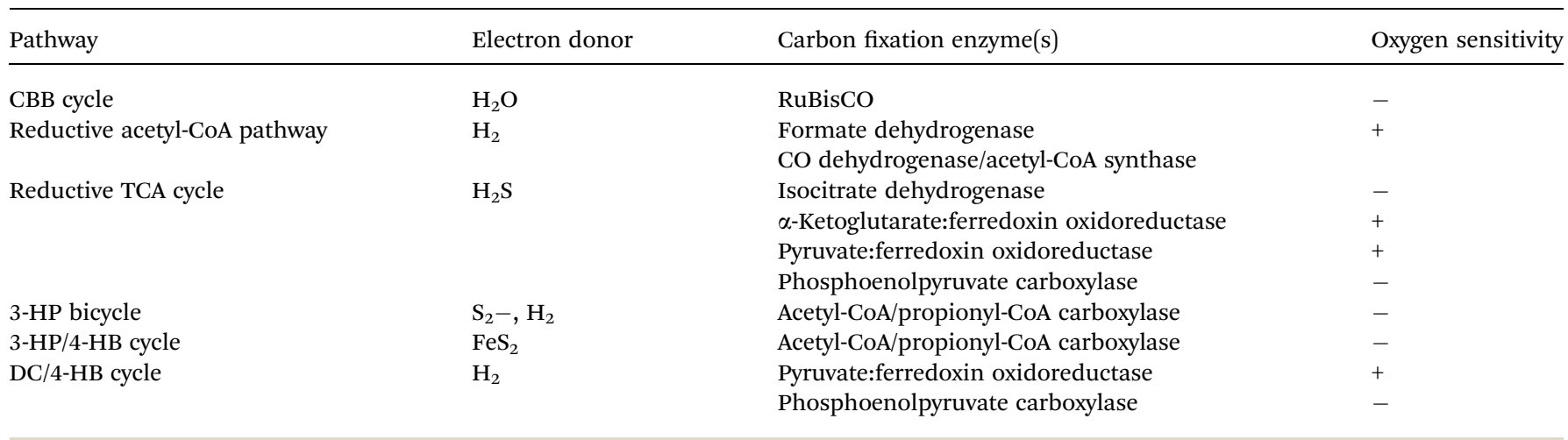

inefficient cycles. This makes it challenging to transplant ATP efficient cycles into aerobic organisms, such as cyanobacteria or E. coli. Of course, intermediate compatibility is another challenge, since foreign intermediates due to non-native gene expression may interfere with the native cell metabolism.

Recently, another potential $\mathrm{CO}_{2}$ assimilation cycle was identified in the dissimilatory phosphite oxidation (DPO) bacterium Candidatus phosphitivorax. ${ }^{104}$ In this process, phosphite is oxidized, thereby providing reducing equivalents, and NADPdependent formate dehydrogenase assimilates $\mathrm{CO}_{2}$ into the formate. Afterwards, the formate is converted into pyruvate through the reductive glycine pathway. ${ }^{105}$ Since phosphite oxidation to phosphate is an efficient electron providing process, this process may drive cell growth under energy limited conditions. The carbon fixation during this process is mainly reduction dependent, which means it is more ATP efficient than the CBB cycle. If an oxygen insensitive formate dehydrogenase was applied, the reductive glycine pathway will be oxygen tolerant. This makes it promising to be transplanted into aerobic organisms.

Instead of understanding, transplanting and engineering native carbon fixation cycles, assembling an artificial carbon fixation cycle with potentially more efficient carbon fixation enzymes is another attractive strategy to improve the carbon fixation efficiency. Bar-Even et al. examined 5000 native existing enzymes for alternative synthetic carbon fixation cycles. ${ }^{101}$ Focusing on the cycle kinetics, thermodynamic feasibility, oxygen tolerance, and high energy efficiency (the amount of NADPH equivalents and ATP equivalents to produce one molecule of the product), they modelled a pathway using PEPc to fix $\mathrm{CO}_{2}$, generating glyoxylate, which was named the malonyl-CoA-oxaloacetateglyoxylate (MOG) pathway. The starting reactions of this pathway overlap with the $\mathrm{C} 4$ carbon fixation pathway in the plant mesophyll cell, but the MOG pathway does include the reactions in the bundle-sheath cells, therefore avoiding the usage of RuBisCO. Computational modelling indicated that this pathway is potentially 2- to 3-fold faster at fixing carbon than the CBB cycle. ${ }^{101}$ Although the whole cycle has not been tested experimentally yet, it has been reported that overexpressing PEPc in Synechocystis PCC 6803 enhanced cell growth under low light conditions. ${ }^{106}$

There is another synthetic carbon fixation cycle, crotonylcoenzyme A (CoA)/ethylmalonyl-CoA/hydroxybutyryl-CoA (CETCH) cycle, which has been examined in vitro. ${ }^{107}$ The $\mathrm{CETCH}$ cycle uses enoyl-CoA carboxylases/reductases, which are not present in autotrophic $\mathrm{CO}_{2}$ fixing organisms, to carboxylate $\mathrm{CO}_{2}$. After enzyme modification or replacement, a well functional version of this cycle, CETCH 5.4, was generated and tested in vitro. This cycle includes 13 enzymes in the carbon fixation cycle and 5 enzymes for auxiliary proofreading (converting the $\mathrm{CO}_{2}$ fixation product glyoxylate into malate) and cofactor regeneration. CETCH 5.4, in which two $\mathrm{CO}_{2}$ molecules were fixed into glyoxylate at the expense of two ATPs and three NADPH, is more energy-efficient than the CBB cycle. ${ }^{107}$

Both the MOG cycle and the CETCH 5.4 are promising CBB cycle alternatives. However, introducing synthetic pathways into living organisms is challenging because of the unpredictable interference between the artificial metabolism and the background native metabolism of the host. Testing the function of the synthetic pathways in vitro while considering and mimicking in vivo conditions can provide useful guides on how to introduce complicated synthetic pathways into living organisms. Even though there are no reports about introducing new complete $\mathrm{CO}_{2}$ fixation pathways into photoautotrophic organisms, there is one example of an artificial pathway to compensate the $\mathrm{CO}_{2}$ loss when pyruvate is converted into acetyl-CoA in Synechococcus elongates PCC $7942 .{ }^{108}$

\section{Further strategies to improve the photosynthetic efficiency}

One of the main reasons that oxygenic photoautotrophic organisms (plants, cyanobacteria and algae) are promising cell factories is that they can directly convert solar energy into chemical energy. Solar energy reaching the earth in one hour is enough for global human activities in one year. If sustainable methods are developed to capture, convert and store solar energy, it will be the infinite fuel for the future. Solar panels are a well-developed technology in capturing and converting solar energy into electricity. However, they do not capture $\mathrm{CO}_{2}$. Photoautotrophic organisms like cyanobacteria and algae are more sustainable in this aspect. However, the solar energy conversion efficiency of even the most efficient photoautotrophic organisms is much lower than that of current commercial solar cells (4.6-6\% versus $18 \%){ }^{102}$

In photoautotrophic organisms, the antenna complexes absorb and transfer solar energy to the photochemical reaction 


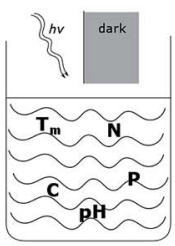

Medium optimization (like $\mathrm{N}, \mathrm{S}$ starvation) Light intensity Light-dark cycle

Inorganic carbon supply Organic carbon supply

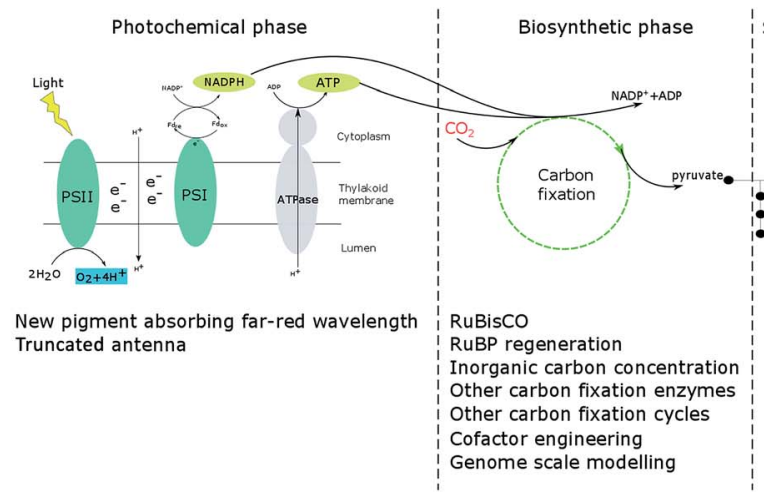

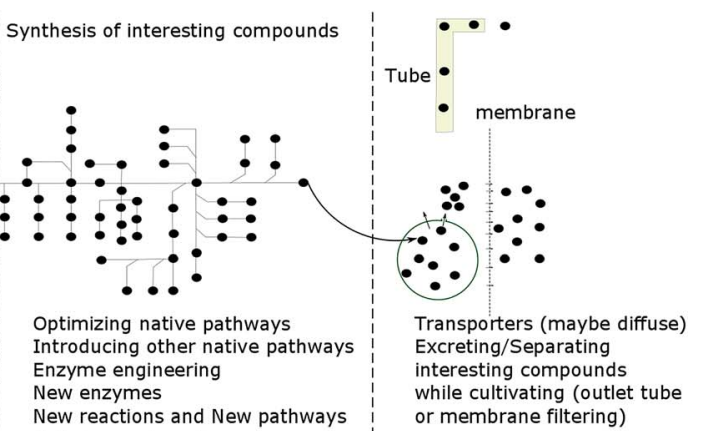

New reactions and New pathways

Cofactor engineering

Genome scale modelling

Fig. 3 Summary of strategies to enhance cell growth and/or product yields in photoautotrophic organisms.

centres, photosystems II and I. During this process, excess absorbed solar energy is dissipated as heat. This often happens in the leaves on the top of the canopies and cells in the surface facing the light source of the algal and cyanobacterial cultures, especially under high light conditions. At the same time, leaves at the bottom of the canopies and cells further from the surface of algal and cyanobacterial cultures will not get enough light. As a result, the energy conversion efficiency of the entire population is low. Therefore, a strategy, using "truncated lightharvesting antenna" (TLA) strains, was developed and used in plants, algae and cyanobacteria to increase the total solar energy conversion efficiency. ${ }^{109-111}$ The strategy is to decrease the antenna size to prevent the top leaves or cells from absorbing excess solar energy. There will be two positive outcomes, one is to reduce light inhibition of the top leaves or surface cells, and the other is to increase light penetration thereby allowing the lower leaves and cells to receive more solar energy. Therefore, the overall solar energy conversion efficiency and production are enhanced. However, it has been reported that the TLA did not enhance Synechocystis PCC 6803 productivity under low light $\left(<200 \mu \mathrm{mol}\right.$ photons $\left.\mathrm{m}^{-2} \mathrm{~s}^{-1}\right)$ and did not enhance cell growth in the early stage $\left(\mathrm{OD}_{735}<1\right) .{ }^{112}$ In contrast, a strain of Chlamydomonas reinhardtii with a truncated antenna showed enhanced oxygen evolution and a higher light saturation point, and strongly enhanced biomass productivities under greenhouse conditions with about $1500 \mu \mathrm{mol}$ photons $\mathrm{m}^{-2} \mathrm{~s}^{-1} .{ }^{109}$ Enhanced growth was also reported in Synechocystis PCC 6803 when $200 \mu \mathrm{mol}$ photons $\mathrm{m}^{-2} \mathrm{~s}^{-1}$ light intensity was applied. ${ }^{113}$ Besides, the truncated antenna benefits cell growth and biomass accumulation in Synechocystis PCC 6803 only under ambient $\mathrm{CO}_{2}$ and high light $\left(1000 \mu \mathrm{mol}\right.$ photons $\left.\mathrm{m}^{-2} \mathrm{~s}^{-1}\right)$ conditions. ${ }^{114}$ Furthermore, another interesting strategy to improve light utilization is to introduce pigments that allow cells to absorb light of longer, red-shifted wavelengths. ${ }^{115}$

In order to convert the output compound(s) of carbon fixation cycles, like PGA in the CBB cycle, to compounds interesting for production, further enzymatic steps are required. Traditional engineering methods, such as introducing genes with known functions from another organism, and new synthetic biology methods like assembling new pathways ${ }^{116}$ and computational modelling $^{41,117}$ are available to optimize this process. In addition to genetic engineering strategies, growth conditions, like nitrogen starvation, medium $\mathrm{pH}$ adjustment, and salt stress, may also have major effects on product yields. Continuously extracting the desired product out of the cells during cultivation may also benefit photosynthesis or/and carbon fixation. ${ }^{6,7}$

\section{Conclusions}

As the only prokaryotic oxygenic photoautotrophic organisms, cyanobacteria are promising green cell factories to produce sustainable bioproducts. During the whole process, from carbon fixation to extraction of products, optimization at every step may contribute to enhancing growth and the product yield (Fig. 3).

In the photochemical phase, RuBisCO, FBA, FBP/SBPase and TK are four enzymes investigated in cyanobacteria, algae and plants as targets of engineering to enhance photosynthesis, growth and/or product formation. Since RuBisCO has a low efficiency and since protein engineering has not resulted in significant improvement in RuBisCO performance, increasing the $\mathrm{CO}_{2}$ concentration near RuBisCO is an alternative strategy. Research is also directed towards finding more efficient carbon fixation cycles, natural or artificial, which could be implemented in engineered cells. With the development of new technologies, like cyanobacterial computational modelling and gene editing technologies, scientists have a better and better understanding of the biosynthetic phase, which will give clues to future studies.

\section{Conflicts of interest}

The authors declare no competing financial interests.

\section{Acknowledgements}

This work was supported by the NordForsk NCoE program "NordAqua" (project \# 82845).

\section{References}

1 C. W. Mullineaux, Co-existence of photosynthetic and respiratory activities in cyanobacterial thylakoid membranes, Biochim. Biophys. Acta, Bioenerg., 2014, 1837(4), 503-511. 
2 D. J. Lea-Smith, P. Bombelli, R. Vasudevan and C. J. Howe, Photosynthetic, respiratory and extracellular electron transport pathways in cyanobacteria, Biochim. Biophys. Acta, Bioenerg., 2016, 1857(3), 247-255.

3 M. R. L. V. Leal, A. S. Walter and J. E. A. Seabra, Sugarcane as an energy source, Biomass Convers. Biorefin., 2013, 3(1), 17-26.

4 D. Tilman, R. Socolow, J. A. Foley, J. Hill, E. Larson, L. Lynd, et al., Beneficial Biofuels-The Food, Energy, and Environment Trilemma, Science, 2009, 325(5938), 270-271.

5 R. H. Wijffels and M. J. Barbosa, An Outlook on Microalgal Biofuels, Science, 2010, 329(5993), 796-799.

6 W. Du, F. Liang, Y. Duan, X. Tan and X. Lu, Exploring the photosynthetic production capacity of sucrose by cyanobacteria, Metab. Eng., 2013, 19, 17-25.

7 B. W. Abramson, B. Kachel, D. M. Kramer and D. C. Ducat, Increased photochemical efficiency in cyanobacteria via an engineered sucrose sink, Plant Cell Physiol., 2016, 57(12), 2451-2460.

8 D. C. Ducat, J. C. Way and P. A. Silver, Engineering cyanobacteria to generate high-value products, Trends Biotechnol., 2011, 29(2), 95-103.

9 N. E. Nozzi, J. W. Oliver and S. Atsumi, Cyanobacteria as a Platform for Biofuel Production, Front. Bioeng. Biotechnol., 2013, 1, 7.

10 V. Singh, D. K. Chaudhary, I. Mani and P. K. Dhar, Recent advances and challenges of the use of cyanobacteria towards the production of biofuels, Renewable Sustainable Energy Rev., 2016, 60, 1-10.

11 D. D. Gütle, T. Roret, S. J. Müller, J. Couturier, S. D. Lemaire, A. Hecker, et al., Chloroplast FBPase and SBPase are thioredoxin-linked enzymes with similar architecture but different evolutionary histories, Proc. Natl. Acad. Sci. U. S. A., 2016, 113(24), 6779-6784.

12 N. Antonovsky, S. Gleizer and R. Milo, Engineering carbon fixation in E. coli: from heterologous RuBisCO expression to the Calvin-Benson-Bassham cycle, Curr. Opin. Biotechnol., 2017, 47, 83-91.

13 D. Fell, Understanding the control of metabolism, Front. Metab., 1997, 2, 300.

14 A. Miller, C. Schlagnhaufer, M. Spalding and S. Rodermel, Carbohydrate regulation of leaf development: prolongation of leaf senescence in Rubisco antisense mutants of tobacco, Photosynth. Res., 2000 Jan, 63(1), 1-8.

15 P. Matt, A. Krapp, V. Haake, H. Mock and M. Stitt, Decreased Rubisco activity leads to dramatic changes of nitrate metabolism, amino acid metabolism and the levels of phenylpropanoids and nicotine in tobacco antisense RBCS transformants, Plant J., 2002, 30(6), 663677.

16 M. Stitt and D. Schulze, Does Rubisco control the rate of photosynthesis and plant growth? An exercise in molecular ecophysiology, Plant, Cell Environ., 1994, 17(5), 465-487.

17 W. P. Quick, U. Schurr, K. Fichtner, E. -D. Schulze, S. R. Rodermel, L. Bogorad, et al., The impact of decreased Rubisco on photosynthesis, growth, allocation and storage in tobacco plants which have been transformed with antisense rbcS, Plant J., 1991, 1(1), 51-58.

18 A. Makino, T. Shimada, S. Takumi, K. Kaneko, M. Matsuoka, K. Shimamoto, et al., Does Decrease in Ribulose-1,5-Bisphosphate Carboxylase by Antisense RbcS Lead to a Higher N-Use Efficiency of Photosynthesis under Conditions of Saturating $\mathrm{CO}_{2}$ and Light in Rice Plants?, Plant Physiol., 1997, 114(2), 483-491.

19 A. Makino and R. F. Sage, Temperature response of photosynthesis in transgenic rice transformed with "sense" or "antisense" rbcS, Plant Cell Physiol., 2007, 48(10), 1472-1483.

20 R. T. Furbank, J. A. Chitty, S. Von Caemmerer and C. Jenkins, Antisense RNA inhibition of RbcS gene expression reduces Rubisco level and photosynthesis in the $\mathrm{C} 4$ plant Flaveria bidentis, Plant Physiol., 1996, 111(3), 725-734.

21 G. S. Hudson, J. R. Evans, S. von Caemmerer, Y. B. Arvidsson and T. J. Andrews, Reduction of ribulose1,5-bisphosphate carboxylase/oxygenase content by antisense RNA reduces photosynthesis in transgenic tobacco plants, Plant Physiol., 1992, 98(1), 294-302.

22 N. A. Eckardt, G. W. Snyder, A. R. Portis Jr and W. L. Ogren, Growth and Photosynthesis under High and Low Irradiance of Arabidopsis thaliana Antisense Mutants with Reduced Ribulose-1,5-Bisphosphate Carboxylase/Oxygenase Activase Content, Plant Physiol., 1997, 113(2), 575-586.

23 S. Von Caemmerer, A. Millgate, G. D. Farquhar and R. T. Furbank, Reduction of Ribulose-1,5-Bisphosphate Carboxylase/Oxygenase by Antisense RNA in the C4 Plant Flaveria bidentis Leads to Reduced Assimilation Rates and Increased Carbon Isotope Discrimination, Plant Physiol., 1997, 113(2), 469-477.

24 K. Siebke, S. von Caemmerer, M. Badger and R. T. Furbank, Expressing an RbcS Antisense Gene in Transgenic Flaveria bidentis Leads to an Increased Quantum Requirement for $\mathrm{CO}_{2}$ Fixed in Photosystems I and II, Plant Physiol., 1997, 115(3), 1163-1174.

25 E. P. Harrison, N. M. Willingham, J. C. Lloyd and C. A. Raines, Reduced sedoheptulose-1,7-bisphosphatase levels in transgenic tobacco lead to decreased photosynthetic capacity and altered carbohydrate accumulation, Planta, 1998, 204(1), 27-36.

26 C. A. Raines, E. P. Harrison and J. C. Lloyd, Minireview: investigating the role of the thiol-regulated enzyme sedoheptulose-1,7-bisphosphatase in the control of photosynthesis, Physiol. Plant., 2000, 110(3), 303-308.

27 T. Lawson, B. Bryant, S. Lefebvre, J. C. Lloyd and C. A. Raines, Decreased SBPase activity alters growth and development in transgenic tobacco plants, Plant, Cell Environ., 2006, 29(1), 48-58.

28 H. Olçer, J. C. Lloyd and C. A. Raines, Photosynthetic capacity is differentially affected by reductions in sedoheptulose-1,7-bisphosphatase activity during leaf development in transgenic tobacco plants, Plant Physiol., 2001, 125, 982-989.

29 E. P. Harrison, Small decreases in SBPase cause a linear decline in the apparent RuBP regeneration rate, but do 
not affect Rubisco carboxylation capacity, J. Exp. Bot., 2001, 52(362), 1779-1784.

30 L. Feng, H. Li, J. Jiao, D. Li, L. Zhou, J. Wan, et al., Reduction in SBPase activity by antisense RNA in transgenic rice plants: effect on photosynthesis, growth, and biomass allocation at different nitrogen levels, J. Plant Biol., 2009, 52(5), 382-394.

$31 \mathrm{~J}$. Kobmann, U. Sonnewald and L. Willmitzer, Reduction of the chloroplastic fructose-1,6-bisphosphatase in transgenic potato plants impairs photosynthesis and plant growth, Plant J., 1994, 6(5), 637-650.

32 M. J. Paul, J. S. Knight, D. Habash, M. A. J. Parry, D. W. Lawlor, S. A. Barnes, et al., Reduction in phosphoribulokinase activity by antisense RNA in transgenic tobacco: effect on $\mathrm{CO}_{2}$ assimilation and growth in low irradiance, Plant J., 1995, 7(4), 535-542.

33 F. Banks, S. Driscoll, M. Parry, D. Lawlor, J. Knight, J. Gray, et al., Decrease in phosphoribulokinase activity by antisense RNA in transgenic tobacco. Relationship between photosynthesis, growth, and allocation at different nitrogen levels, Plant Physiol., 1999, 119(3), 1125-1136.

34 M. J. Paul, S. P. Driscoll, P. J. Andralojc, J. S. Knight, J. C. Gray and D. W. Lawlor, Decrease of phosphoribulokinase activity by antisense RNA in transgenic tobacco: definition of the light environment under which phosphoribulokinase is not in large excess, Planta, 2000, 211(1), 112-119.

35 G. D. Price, J. R. Evans, S. von Caemmerer, J. W. Yu and M. R. Badger, Specific reduction of chloroplast glyceraldehyde-3-phosphate dehydrogenase activity by antisense RNA reduces $\mathrm{CO}_{2}$ assimilation via a reduction in ribulose bisphosphate regeneration in transgenic tobacco plants, Planta, 1995, 195(3), 369-378.

36 S. Henkes, U. Sonnewald, R. Badur, R. Flachmann and M. Stitt, A Small Decrease of Plastid Transketolase Activity in Antisense Tobacco Transformants Has Dramatic Effects on Photosynthesis and Phenylpropanoid Metabolism, Plant Cell, 2001, 13, 535-551.

37 V. Haake, M. Geiger, P. Walch-Liu, C. Engels, R. Zrenner and M. Stitt, Changes in aldolase activity in wild-type potato plants are important for acclimation to growth irradiance and carbon dioxide concentration, because plastid aldolase exerts control over the ambient rate of photosynthesis across a range of growth condition, Plant J., 1999, 17(5), 479-489.

38 V. Haake, R. Zrenner, U. Sonnewald and M. Stitt, A moderate decrease of plastid aldolase activity inhibits photosynthesis, alters the levels of sugars and starch, and inhibits growth of potato plants, Plant J., 1998, 14(2), 147157.

39 M. Eisenhut, W. Ruth, M. Haimovich, H. Bauwe, A. Kaplan and M. Hagemann, The photorespiratory glycolate metabolism is essential for cyanobacteria and might have been conveyed endosymbiontically to plants, Proc. Natl. Acad. Sci. U. S. A., 2008, 105(44), 17199-17204.

40 D. M. Kramer and J. R. Evans, The Importance of Energy Balance in Improving Photosynthetic Productivity, Plant Physiol., 2011, 110, 166652.
41 H. Knoop, M. Gründel, Y. Zilliges, R. Lehmann, S. Hoffmann, W. Lockau, et al., Flux balance analysis of cyanobacterial metabolism: the metabolic network of Synechocystis sp, PCC 6803, PLoS Comput. Biol., 2013, 9(6), e1003081.

42 Y. Savir, E. Noor, R. Milo and T. Tlusty, Cross-species analysis traces adaptation of Rubisco toward optimality in a low-dimensional landscape, Proc. Natl. Acad. Sci. U. S. A., 2010, $107(8)$, 3475-3480.

43 G. G. B. Tcherkez, G. D. Farquhar and T. J. Andrews, Despite slow catalysis and confused substrate specificity, all ribulose bisphosphate carboxylases may be nearly perfectly optimized, Proc. Natl. Acad. Sci. U. S. A., 2006, 103(19), 7246-7251.

44 R. A. Studer, P.-A. Christin, M. A. Williams and C. A. Orengo, Stability-activity tradeoffs constrain the adaptive evolution of RubisCO, Proc. Natl. Acad. Sci. U. S. A., 2014, 111(6), 2223-2228.

45 P. L. Cummins, B. Kannappan and J. E. Gready, Directions for Optimization of Photosynthetic Carbon Fixation: RuBisCO's Efficiency May Not Be So Constrained After All, Front. Plant. Sci., 2018, 9.

46 P. Durão, H. Aigner, P. Nagy, O. Mueller-Cajar, F. U. Hartl and M. Hayer-Hartl, Opposing effects of folding and assembly chaperones on evolvability of Rubisco, Nat. Chem. Biol., 2015, 11(2), 148-155.

47 M. Faulkner, J. Rodriguez-Ramos, G. F. Dykes, S. V. Owen, S. Casella, D. M. Simpson, et al., Direct characterization of the native structure and mechanics of cyanobacterial carboxysomes, Nanoscale, 2017, 9(30), 10662-10673.

48 F. W. Li, J. C. Villarreal and P. Szövényi, Hornworts: An Overlooked Window into Carbon-Concentrating Mechanisms, Trends Plant Sci., 2017, 22(4), 275-277.

49 R. F. Sage, Photosynthetic efficiency and carbon concentration in terrestrial plants: the C4 and CAM solutions, J. Exp. Bot., 2014, 65(13), 3323-3325.

50 S. M. Whitney, R. L. Houtz and H. Alonso, Advancing Our Understanding and Capacity to Engineer Nature's $\mathrm{CO}_{2}$ Sequestering Enzyme, Rubisco, Plant Physiol., 2011, 155(1), 27-35.

51 T. Hauser, L. Popilka, F. U. Hartl and M. Hayer-Hartl, Role of auxiliary proteins in Rubisco biogenesis and function, Nat. Plants, 2015, 1(6), 15065.

52 H. Aigner, R. H. Wilson, A. Bracher, L. Calisse, J. Y. Bhat, F. U. Hartl, et al., Plant RuBisCo assembly in E. coli with five chloroplast chaperones including BSD2, Science, 2017, 358(6368), 1272-1278.

53 S. M. Whitney, P. Baldet, G. S. Hudson and T. J. Andrews, Form I Rubiscos from non-green algae are expressed abundantly but not assembled in tobacco chloroplasts, Plant J., 2001, 26(5), 535-547.

54 M. T. Lin, A. Occhialini, P. J. Andralojc, M. A. J. Parry and M. R. Hanson, A faster Rubisco with potential to increase photosynthesis in crops, Nature, 2014, 513(7519), 547-550.

55 A. Occhialini, M. T. Lin, P. J. Andralojc, M. R. Hanson and M. A. J. Parry, Transgenic tobacco plants with improved cyanobacterial Rubisco expression but no extra assembly 
factors grow at near wild-type rates if provided with elevated $\mathrm{CO}_{2}$, Plant J., 2016, 85(1), 148-160.

56 S. Atsumi, W. Higashide and J. C. Liao, Direct photosynthetic recycling of carbon dioxide to isobutyraldehyde, Nat. Biotechnol., 2009, 27(12), 1177-1180.

57 G. D. Price, Inorganic carbon transporters of the cyanobacterial CO2 concentrating mechanism, Photosynth Res, 2011, 109(1-3), 47-57.

58 N. A. Kamennaya, S. E. Ahn, H. Park, R. Bartal, K. A. Sasaki, H. Y. Holman, et al. Installing extra bicarbonate transporters in the cyanobacterium Synechocystis sp. PCC6803 enhances biomass production, Metab. Eng., 2015, 29, 76-85.

59 C. A. Kerfeld and M. R. Melnicki, Assembly, function and evolution of cyanobacterial carboxysomes, Curr. Opin. Plant Biol., 2016, 31, 66-75.

60 W. Bonacci, P. K. Teng, B. Afonso, H. Niederholtmeyer, P. Grob and P. A. Silver, Modularity of a carbon-fixing protein organelle, Proc. Natl. Acad. Sci. U. S. A., 2012, 109(2), 478-483.

61 J. C. Cameron, S. C. Wilson, S. L. Bernstein and C. A. Kerfeld, Biogenesis of a bacterial organelle: the carboxysome assembly pathway, Cell, 2013, 155(5), 11311140.

62 F. Cai, S. L. Bernstein, S. C. Wilson and C. A. Kerfeld, Production and Characterization of Synthetic Carboxysome Shells with Incorporated Luminal Proteins, Plant Physiol., 2016, 170(3), 1868-1877.

63 W. W. Cleland, T. J. Andrews, S. Gutteridge, F. C. Hartman and G. H. Lorimer, Mechanism of Rubisco: The Carbamate as General Base, Chem. Rev., 1998, 98(2), 549-562.

64 J. Y. Bhat, G. Miličić, G. Thieulin-Pardo, A. Bracher, A. Maxwell, S. Ciniawsky, et al., Mechanism of Enzyme Repair by the AAA+ Chaperone Rubisco Activase, Mol. Cell, 2017, 67(5), 744-756.

65 L. A. Li, L. Janet and R. T. F. Gibson, The Rubisco activase (rca) gene is located downstream from rbcS in Anabaena sp. strain CA and is detected in other Anabaena/Nostoc strains, Plant Mol. Biol., 1993, 21(5), 753-764.

66 O. Koksharova, M. Schubert, S. Shestakov and R. Cerff, Genetic and biochemical evidence for distinct key functions of two highly divergent GAPDH genes in catabolic and anabolic carbon flow of the cyanobacterium Synechocystis sp. PCC 6803, Plant Mol. Biol., 1998, 36(1), 183-194.

67 M. Tamoi, T. Miyazaki, T. Fukamizo and S. Shigeoka, The Calvin cycle in cyanobacteria is regulated by CP12 via the $\mathrm{NAD}(\mathrm{H}) / \mathrm{NADP}(\mathrm{H})$ ratio under light/dark conditions, Plant J., 2005, 42(4), 504-513.

68 S. V. Caemmerer and J. A. Berry, A Biochemical Model of Photosynthetic $\mathrm{CO}_{2}$ Assimilation in Leaves of C3 Species, Planta, 1980, 149(1), 78-90.

69 C. A. Raines, The Calvin cycle revisited, Photosynth. Res., 2003, 75(1), 1-10.

70 X.-G. Zhu, E. de Sturler and S. P. Long, Optimizing the Distribution of Resources between Enzymes of Carbon Metabolism Can Dramatically Increase Photosynthetic
Rate: A Numerical Simulation Using an Evolutionary Algorithm, Plant Physiol., 2007, 145(2), 513-526.

71 A. Flechner, W. Gross, W. Martin and C. Schnarrenberger, Chloroplast class I and class II aldolases are bifunctional for fructose-1,6-biphosphate and sedoheptulose-1,7biphosphate cleavage in the Calvin cycle, FEBS Lett., 1999, 447, 200-202.

72 F. Liang, E. Englund, P. Lindberg and P. Lindblad, Engineered cyanobacteria with enhanced growth show increased ethanol production and higher biofuel to biomass ratio, Metab. Eng., 2018, 46, 51-59.

73 A. J. Serrato, E. M. Yubero-Serrano, L. M. Sandalio, J. MuÑoz-Blanco, A. Chueca, J. L. Caballero, et al. CpFBPaseII, a novel redox-independent chloroplastic isoform of fructose-1,6-bisphosphatase, Plant, Cell Environ., 2009, 32(7), 811-827.

74 M. Chiadmi, A. Navaza, M. Miginiac-Maslow, J. P. Jacquot and J. Cherfils, Redox signalling in the chloroplast: structure of oxidized pea fructose-1,6-bisphosphate phosphatase, EMBO J., 1999, 18(23), 6809-6815.

75 D. Schimkat, D. Heineke and H. W. Heldt, Regulation of sedoheptulose-1,7-bisphosphatase by sedoheptulose-7phosphate and glycerate, and of fructose-1,6bisphosphatase by glycerate in spinach chloroplasts, Planta, 1990, 181, 97-103.

76 T. Mettler, T. Muhlhaus, D. Hemme, M.-A. Schottler, J. Rupprecht, A. Idoine, et al., Systems Analysis of the Response of Photosynthesis, Metabolism, and Growth to an Increase in Irradiance in the Photosynthetic Model Organism Chlamydomonas reinhardtii, Plant Cell, 2014, 26(6), 2310-2350.

77 T. Iwaki, K. Haranoh, N. Inoue, K. Kojima, R. Satoh, T. Nishino, et al., Expression of foreign type I ribulose-1,5bisphosphate carboxylase/oxygenase (EC 4.1.1.39) stimulates photosynthesis in cyanobacterium Synechococcus PCC7942 cells, Photosynth. Res., 2006, 88(3), 287-297.

78 A. M. Ruffing, Borrowing genes from Chlamydomonas reinhardtii for free fatty acid production in engineered cyanobacteria, J. Appl. Phycol., 2013, 25(5), 1495-1507.

79 A. M. Ruffing, Improved Free Fatty Acid Production in Cyanobacteria with Synechococcus sp. PCC 7002 as Host, Front. Bioeng. Biotechnol., 2014, 2, 17.

80 M. Kanno, A. L. Carroll and S. Atsumi, Global metabolic rewiring for improved $\mathrm{CO}_{2}$ fixation and chemical production in cyanobacteria, Nat. Commun., 2017, 8, 14724.

81 F. Liang and P. Lindblad, Synechocystis PCC 6803 overexpressing RuBisCO grow faster with increased photosynthesis, Metab. Eng. Commun., 2017, 4, 29-36.

82 F. Liang and P. Lindblad, Effects of overexpressing photosynthetic carbon flux control enzymes in the cyanobacterium Synechocystis PCC 6803, Metab. Eng., 2016, 38, 56-64.

83 A. J. De Porcellinis, H. Nørgaard, L. M. F. Brey, S. M. Erstad, P. R. Jones, J. L. Heazlewood, et al., Overexpression of bifunctional fructose-1,6-bisphosphatase/sedoheptulose1,7-bisphosphatase leads to enhanced photosynthesis and 
global reprogramming of carbon metabolism in Synechococcus sp. PCC 7002, Metab. Eng., 2018, 47, 170-183. 84 W. Ma, D. Shi, Q. Wang, L. Wei and H. Chen, Exogenous expression of the wheat chloroplastic fructose-1,6bisphosphatase gene enhances photosynthesis in the transgenic cyanobacterium, Anabaena PCC7120, J. Appl. Phycol., 2005, 17(3), 273-280.

85 W. Dejtisakdi and S. M. Miller, Overexpression of Calvin cycle enzyme fructose 1,6-bisphosphatase in Chlamydomonas reinhardtii has a detrimental effect on growth, Algal Res., 2016, 14, 116-126.

86 M. Tamoi, M. Nagaoka, Y. Miyagawa and S. Shigeoka, Contribution of fructose-1,6-bisphosphatase and sedoheptulose-1,7- bisphosphatase to the photosynthetic rate and carbon flow in the Calvin cycle in transgenic plants, Plant Cell Physiol., 2006, 47(3), 380-390.

87 Y. Miyagawa, M. Tamoi and S. Shigeoka, Overexpression of a cyanobacterial fructose-1,6-/sedoheptulose-1,7bisphosphatase in tobacco enhances photosynthesis and growth, Nat. Biotechnol., 2001, 19, 965-969.

88 T. Ogawa, M. Tamoi, A. Kimura, A. Mine, H. Sakuyama, E. Yoshida, et al., Enhancement of photosynthetic capacity in Euglena gracilis by expression of cyanobacterial fructose1,6-/sedoheptulose-1,7-bisphosphatase leads to increases in biomass and wax ester production, Biotechnol. Biofuels, $2015,8,80$.

89 I. H. Köhler, U. M. Ruiz-Vera, A. VanLoocke, M. L. Thomey, T. Clemente, S. P. Long, et al., Expression of cyanobacterial FBP/SBPase in soybean prevents yield depression under future climate conditions, J. Exp. Bot., 2017, 68(3), 715-726.

90 S. Lefebvre, T. Lawson, M. Fryer, O. V. Zakhleniuk, J. C. Lloyd and C. a Raines, Increased sedoheptulose-1,7bisphosphatase activity in transgenic tobacco plants stimulates photosynthesis and growth from an early stage in development, Plant Physiol., 2005, 138(1), 451-460.

91 L. Feng, Y. Han, G. Liu, B. An, J. Yang, G. Yang, et al. Overexpression of sedoheptulose-1,7-bisphosphatase enhances photosynthesis and growth under salt stress in transgenic rice plants, Funct. Plant Biol., 2007, 34(9), 822.

92 D. M. Rosenthal, A. M. Locke, M. Khozaei, C. A. Raines, S. P. Long and D. R. Ort, Over-expressing the C(3) photosynthesis cycle enzyme sedoheptulose-1-7 bisphosphatase improves photosynthetic carbon gain and yield under fully open air $\mathrm{CO}(2)$ fumigation (FACE), $B M C$ Plant Biol., 2011, 11(1), 123.

93 A. J. Simkin, P. E. Lopez-Calcagno, P. A. Davey, L. R. Headland, T. Lawson, S. Timm, et al. Simultaneous stimulation of sedoheptulose 1,7-bisphosphatase, fructose 1,6-bisphosphate aldolase and the photorespiratory glycine decarboxylase- $\mathrm{H}$ protein increases $\mathrm{CO}_{2}$ assimilation, vegetative biomass and seed yield in Arabidopsis, Plant Biotechnol. J., 2017, 15(7), 805-816.

94 K. Uematsu, N. Suzuki, T. Iwamae, M. Inui and H. Yukawa, Increased fructose 1,6-bisphosphate aldolase in plastids enhances growth and photosynthesis of tobacco plants, $J$. Exp. Bot., 2012, 63(8), 3001-3009.
95 A. Hatano-Iwasaki and K. Ogawa, Biomass production is promoted by increasing an aldolase undergoing glutathionylation in Arabidopsis thaliana, Int. J. Plant Dev. Biol., 2012, 1-8.

96 A. J. Simkin, L. McAusland, L. R. Headland, T. Lawson and C. A. Raines, Multigene manipulation of photosynthetic carbon assimilation increases $\mathrm{CO}_{2}$ fixation and biomass yield in tobacco, J. Exp. Bot., 2015, 66(13), 4075-4090.

97 B. Yang, J. Liu, X. Ma, B. Guo, B. Liu, T. Wu, et al. Genetic engineering of the Calvin cycle toward enhanced photosynthetic $\mathrm{CO}_{2}$ fixation in microalgae, Biotechnol. Biofuels, 2017, 10(1), 229.

98 M. Khozaei, S. Fisk, T. Lawson, Y. Gibon, R. Sulpice, M. Stitt, et al. Overexpression of plastid transketolase in tobacco results in a thiamine auxotrophic phenotype, Plant Cell, 2015, 27(2), 432-447.

99 Y. Suzuki, E. Kondo and A. Makino, Effects of cooverexpression of the genes of Rubisco and transketolase on photosynthesis in rice, Photosynth Res., 2017, 131(3), 281-289.

100 I. A. Berg, D. Kockelkorn, W. H. Ramos-Vera, R. F. Say, J. Zarzycki, M. Hügler, et al. Autotrophic carbon fixation in archaea, Nat. Rev. Microbiol., 2010, 8(6), 447-460.

101 A. Bar-Even, E. Noor, N. E. Lewis and R. Milo, Design and analysis of synthetic carbon fixation pathways, Proc. Natl. Acad. Sci. U. S. A., 2010, 107(19), 8889-8894.

102 N. J. Claassens, D. Z. Sousa, V. A. P. M. Dos Santos, W. M. De Vos and J. Van Der Oost, Harnessing the power of microbial autotrophy, Nat. Rev. Microbiol., 2016, 14(11), 692-706.

103 C. A. Cotton, C. Edlich-Muth and A. Bar-Even, Reinforcing carbon fixation: $\mathrm{CO}_{2}$ reduction replacing and supporting carboxylation, Curr. Opin. Biotechnol., 2018, 49, 49-56.

104 I. A. Figueroa, T. P. Barnum, P. Y. Somasekhar, C. I. Carlström, A. L. Engelbrektson and J. D. Coates, Metagenomics-guided analysis of microbial chemolithoautotrophic phosphite oxidation yields evidence of a seventh natural $\mathrm{CO}_{2}$ fixation pathway, Proc. Natl. Acad. Sci. U. S. A., 2017, (5), 201715549.

105 A. Bar-Even, Formate Assimilation: The Metabolic Architecture of Natural and Synthetic Pathways, Biochemistry, 2016, 55(28), 3851-3863.

106 C. Durall, N. Rukminasari and P. Lindblad, Enhanced growth at low light intensity in the cyanobacterium Synechocystis PCC 6803 by overexpressing phosphoenolpyruvate carboxylase, Algal Res., 2016, 16, 275-281.

107 T. Schwander, L. Schada von Borzyskowski, S. Burgener, N. S. Cortina and T. J. Erb, A synthetic pathway for the fixation of carbon dioxide in vitro, Science, 2016, 354(6314), 900-904.

108 H. Yu, X. Li, F. Duchoud, D. S. Chuang and J. C. Liao, Augmenting the Calvin-Benson-Bassham cycle by a synthetic malyl-CoA-glycerate carbon fixation pathway, Nat. Commun., 2018, 9(1), 1-10.

109 J. E. W. Polle, S.-D. Kanakagiri and A. Melis, tla1, a DNA insertional transformant of the green alga 
Chlamydomonas reinhardtii with a truncated lightharvesting chlorophyll antenna size, Planta, 2003, 217(1), 49-59.

110 H. Kirst, C. Formighieri and A. Melis, Maximizing photosynthetic efficiency and culture productivity in cyanobacteria upon minimizing the phycobilisome lightharvesting antenna size, Biochim. Biophys. Acta, Bioenerg., 2014, 1837(10), 1653-1664.

111 T. Gabilly, K. K. Niyogi and P. G. Lemaux, Photosynthetic antenna engineering to improve crop yields, Planta, 2017, 245(5), 1009-1020.

112 L. E. Page, M. Liberton and H. B. Pakrasi, Reduction of photoautotrophic productivity in the cyanobacterium Synechocystis sp. strain PCC 6803 by phycobilisome antenna truncation, Appl. Environ. Microbiol., 2012, 78(17), 6349-6351.

113 J. H. Kwon, G. Bernát, H. Wagner, M. Rögner and S. Rexroth, Reduced light-harvesting antenna: consequences on cyanobacterial metabolism and photosynthetic productivity, Algal Res., 2013, 2(3), 188-195.
114 D. J. Lea-Smith, P. Bombelli, J. S. Dennis, S. A. Scott, A. G. Smith and C. J. Howe, Phycobilisome-Deficient Strains of Synechocystis sp. PCC 6803 Have Reduced Size and Require Carbon-Limiting Conditions to Exhibit Enhanced Productivity, Plant Physiol., 2014, 165(2), 705714.

115 M. Chen, M. Schliep, R. D. Willows, Z. Cai, B. A. Beilan and H. Scheer, A red-shifted chlorophyll, Science, 2010, 329, 1318-1320.

116 T. J. Erb, P. R. Jones and A. Bar-Even, Synthetic metabolism: metabolic engineering meets enzyme design, Curr. Opin. Chem. Biol., 2017, 37, 56-62.

117 J. T. Broddrick, B. E. Rubin, D. G. Welkie, N. Du, N. Mih, S. Diamond, et al. Unique attributes of cyanobacterial metabolism revealed by improved genome-scale metabolic modeling and essential gene analysis, Proc. Natl. Acad. Sci. U. S. A., 2016, 113(51), E8344-E8353. 